\title{
Connections of Visual Areas of the Upper Temporal Lobe of Owl Monkeys: The MT Crescent and Dorsal and Ventral Subdivisions of FST
}

\author{
Jon H. Kaas and Anne Morel \\ Department of Psychology, Vanderbilt University, Nashville, Tennessee 37240
}

An oval of cortex of moderately dense myelination just ventral to the middle temporal visual area (MT) with input from MT has been referred to as the fundal area of the superior temporal sulcus (FST). Injections of the tracer WGA-HRP into dorsal ( $F S T_{D}$ ) and ventral (FST $_{v}$ ) halves of FST revealed that only $\mathrm{FST}_{\mathrm{D}}$ has connections with MT. $\mathrm{FST}_{\mathrm{V}}$ has connections instead with small patches of cortex that string together like beads to form a ring or crescent $\left(\mathrm{MT}_{\mathrm{c}}\right)$ around most of $\mathrm{MT}$. The patches in $\mathbf{M T}_{\mathrm{c}}$ stain densely for myelin or cytochrome oxidase, and they are embedded in a less densely stained matrix. The connections of $\mathrm{FST}_{\mathrm{D}}$ associate the area with the dorsal stream of processing directed toward posterior parietal cortex and important in spatial aspects of vision. Thus, FST $_{\mathrm{D}}$ has direct connections with ventral posterior parietal cortex (VPP), and connections with MT, the medial superior temporal (MST), and dorsomedial (DM) visual areas, all areas that relay to posterior parietal cortex. In contrast, $\mathrm{FST}_{\mathrm{v}}$ does not appear to have connections with either VPP or MST, and only sparse connections with DM. Rather, major connections of FST $_{v}$ are with inferior temporal cortex. Thus, FST $_{v}$ is more associated with the ventral stream of processing related to object vision. However, both $\mathrm{FST}_{V}$ and $\mathrm{FST}_{\mathrm{D}}$ have connections with area 18 or V-II, the dorsolateral visual area, the frontal eye field, and a frontal visual area. Interhemispheric connections of $\mathrm{FST}_{\mathrm{D}}$ include $\mathrm{FST}_{\mathrm{D}}$, MT, and MST, while interhemispheric connections of $\mathrm{FST}_{\mathrm{v}}$ include $\mathrm{FST}_{\mathrm{v}}$ and $\mathrm{MT}_{\mathrm{c}}$.

[Key words: primates, visual cortex, frontal eye field, middle temporal visual area, area 18, inferior temporal cortex]

The present study is part of an effort to determine the structural organization of the upper temporal lobe of primates. Our overall goal is to identify the processing areas of presumed functional significance in this part of the visual system, and determine how they are interconnected with other parts of the visual system. Here we consider the cortical connections of FST [the fundal area of the superior temporal sulcus (STS)] just ventral to the middle temporal area, MT (Allman and Kaas, 1971).

FST is a recently defined subdivision of visual cortex in primates. Early investigations of MT connections in owl monkeys (Weller et al., 1984) and macaque monkeys (Maunsell and Van Essen, 1983) revealed that MT projections include cortex just

\footnotetext{
Received June 4, 1992; revised July 21, 1992; accepted July 27, 1992.

This work was supported by NEI Grant EY-02686.

Correspondence should be addressed to Jon H. Kaas, Department of Psychology, 301 Wilson Hall, Vanderbilt University, Nashville, TN 37240.

a Present address: Laboratory for Functional Neurosurgery, Neurosurgery Clinic, 100 Rämistrasse, University Hospital, Zürich, Switzerland, CH-809l.

Copyright (C) 1993 Society for Neuroscience 0270-6474/93/130534-13\$05.00/0
}

rostromedial to MT above the superior temporal fissure, and cortex just ventral to MT on the ventral bank and lip of the superior temporal fissure (also see Spatz and Tigges, 1972). Both groups of investigators were uncertain if these two projection zones represented locations in two distinct visual areas or two locations in one area. Weller et al. (1984) referred to the whole region as the superior temporal area, ST, and Maunsell and Van Essen (1983) termed the complete projection zone the medial superior temporal area, MST. Subsequently, Desimone and Ungerleider (1986) and Ungerleider and Desimone (1986b) studied the connections of MT, the physiology of neurons in MT and adjacent cortex, and the mycloarchitccture of the region. These investigators concluded that the two projection zones were different areas. First, they redefined MST as a smaller field with a high proportion of directionally selective neurons and a crude visuotopic organization. Second, they distinguished the FST as a field with distinctive myeloarchitecture, fewer directionally selective neurons, and neurons with receptive fields that often included the center of vision and parts of the ipsilateral visual hemifield. In a subsequent investigation (Krubitzer and Kaas, 1990a), the apparent homologs of MST and FST were identified in owl monkeys and several other primates by connections with MT and myeloarchitecture. MST was described as an oval of cortex with moderately dense myelination on the rostromedial border of MT, while FST was denoted as a field of similar myelination that extended rostroventrally from the MT border, along the ventral bank and lip of the STS in owl monkeys.

In the present investigation, we attempted to study the cortical connections of FST in owl monkeys by placing injections of WGA-HRP directly in the area. Connections of FST have been recently studied in this manner in macaque monkeys (Boussaoud et al., 1990). Our results unexpectedly provided evidence for subdividing FST into two distinct areas, a dorsal FST $\left(\mathrm{FST}_{\mathrm{D}}\right)$ and a ventral FST $\left(\mathrm{FST}_{\mathrm{v}}\right)$, as well as evidence for a narrow, crescent-like area bordering much of MT that we term the MT crescent $\left(\mathrm{MT}_{\mathrm{C}}\right)$. The connections of $\mathrm{FST}_{\mathrm{D}}$ associate the field with a dorsal (parietal) stream of processing areas for spatial vision, while the connections of $\mathrm{FST}_{\mathrm{v}}$ associate this field and $\mathrm{MT}_{\mathrm{C}}$ with a ventral (temporal) stream of processing for object vision (Ungerleider and Mishkin, 1982).

\section{Materials and Methods}

Wheat germ agglutinin conjugated with horseradish peroxidase (WGAHRP) or fluorescent dyes were injected into visual cortex of the upper temporal lobe in seven adult owl monkeys, Aotus trivirgatus. Procedures closely followed those used previously in the laboratory (c.g., Krubitzer and Kaas, 1990a; Morel and Kaas, 1992). In brief, injections were placed in the expected locations of previously defined visual areas by reference 
to surface landmarks. After appropriate survival periods, the monkeys were perfused and their brains removed. Cortex was separated from the rest of the brain, manually flattened (see Huerta et al., 1987), and cut parallel to the surface. Sets of sections were processed for HRP, myelin, or cytochrome oxidase (CO). In the two brains with injections of fluorescent dyes, a set of sections was mounted without further processing. Injection sites and connection patterns were drawn from individual sections, and results from different sections were superimposed on a representative drawing using blood vessels and other fcaturcs for local alignment. Architectonic borders were determined from CO- or myelinstained sections, and aligned on the summary drawing. This resulted in surface views of cortex showing injection sites, connection patterns, and architectonic features.

At the beginning of each experiment, each monkey was anesthetized with injections of ketamine hydrochloride $(30-50 \mathrm{mg} / \mathrm{kg}$; White et al., $1982)$ and acepromazine maleate $(1 \mathrm{mg} / \mathrm{kg})$, supplemented as needed to maintain surgical levels of anesthesia with injections of $10-20 \%$ of the original dose. Using aseptic surgical procedures, the skin was cut and retracted and a small amount of bone was removed to expose the region of the caudal tip of the superior temporal sulcus in the upper temporal lobe. In six owl monkeys, small amounts of WGA-HRP $(0.03-0.05 \mu \mathrm{l}$ of $2 \%$ in saline) or Fluoro-Ruby $(0.2 \mu \mathrm{l}$ of $10 \%$ solution; see Schmued et al., 1990) were injected in the expcctcd location of the fundal area of the superior temporal sulcus (FST), as previously identified in owl monkeys (Krubitzer and Kaas, 1990a). In one additional owl monkey, injections of WGA-HRP or fast blue $(0.2 \mu 1$ of $3 \%$ solution $)$ were placed in the expected location of the middle temporal crescent $\left(\mathrm{MT}_{\mathrm{C}}\right)$, as defined in the present study, and an injection of diamidino yellow $(0.2 \mu \mathrm{l}$ of $3 \%$ solution) was placed in the middle temporal visual area (MT). After the injections, the opening in the skull was sealed with a cap of dental acrylic, the skin was sutured, antibiotics were given, and the animals were monitored carefully during recovery from anesthesia. After survival periods of 2-4 d, each animal was given a lethal injection of barbiturate anesthetic, and perfused with $0.9 \%$ saline followed by fixative ( $2 \%$ buffered paraformaldehyde) and then fixative with $10 \%$ sucrose.

For histology, each brain was removed immcdiatcly after perfusion, hemispheres were separated from the brain stem, sulci were opened by blunt dissection, and cortex was separated from the white matter, flattened between glass plates, and submerged in 30\% buffered sucrose. After 12-15 hr, the flattened hemispheres were cut parallel to the cortical surface into $40 \mu \mathrm{m}$ sections. Every third section was processed for HRP with tetramethylbenzidine following the procedures of Gibson et al. (1984). A second series of every third section was processed for levels of CO activity (Wong-Riley, 1979), and a third set was stained for myelin (Gallyas, 1979). In brains with injections of fluorescent dyes, a set of unprocessed sections was mounted for examination with a fluorescent microscope.

\section{Results}

Ipsilateral and contralateral cortical connections of dorsal $\mathrm{FST}_{\mathrm{D}}$ and ventral $\mathrm{FST}_{\mathrm{v}}$ portions of FST were determined by injecting WGA-HRP or a fluorescent tracer in to these regions or into one of the target areas. Connection patterns were subsequently related to architectonic subdivisions of visual cortex that were revealed by stains for myelin or $\mathrm{CO}$.

Architectonic features of $F S T_{\nu}, F S T_{D}$, and $M T_{C}$

Previously, we have described the characteristics of a number of subdivisions of visual and other cortex in tangential sections processed for myelin or CO (e.g., Krubitzer and Kaas, 1990a; Morel and Kaas, 1992). Areas 17, 18, MT, dorsomedial visual area (DM), 3b, and primary auditory area plus the rostral auditory area are usually easily distinguished, and when denoted, they provide useful landmarks. Other areas such as ventral posterior parietal cortex (VPP), dorsolateral visual area (DL), and frontal eye field (FEF) can be recognized in favorable preparations, but often locations of their boundaries can only be estimated relative to other fields and surface features.

The areas of importance for the present study are $\mathrm{MT}, \mathrm{MT}_{\mathrm{C}}$, $\mathrm{FST}_{\mathrm{D}}$, and $\mathrm{FST}_{\mathrm{v}}$ (Fig. 1). MT is easily recognized as an oval of

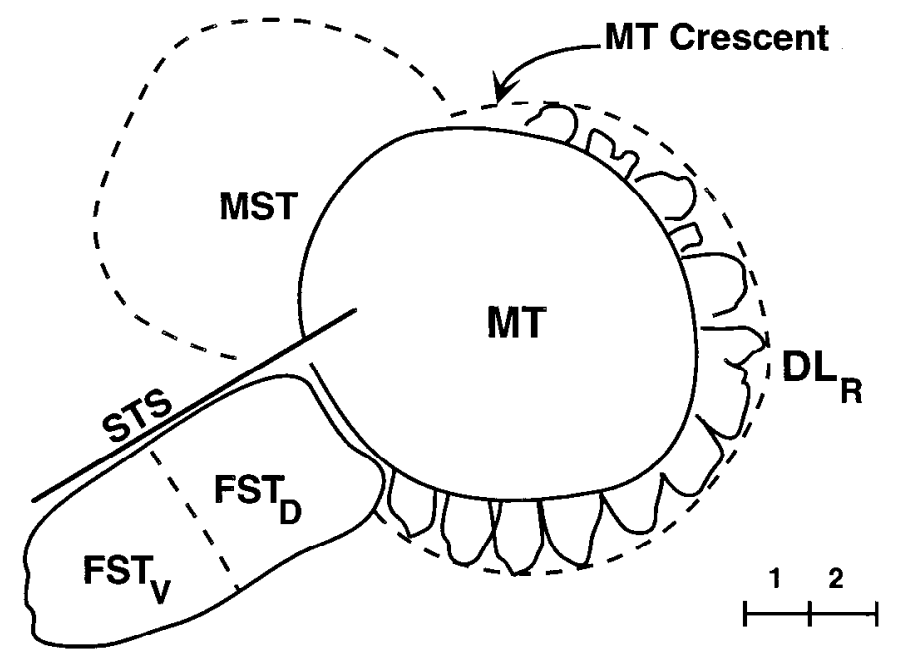

Figure 1. Visual areas of the MT region of owl monkeys. The drawing was made from a freshly cut, wet, unstained section cut parallel to the surface of flattened cortex. In such a preparation, densely myelinated regions are white and less myelinated regions are gray. MT was apparent as a densely myelinated oval, and the $\mathrm{MT}_{C}$ appeared as a series of myelinated patches. MST, FST ${ }_{D}$, and $\mathrm{FST}_{\mathrm{V}}$ were moderately myelinated. The fundus of the STS is indicated. Broken lines indicate estimated boundaries. See Figure 4 for locations on the brain. Scale bar, $2 \mathrm{~mm}$.

tissue that stains darkly for myelin (Allman and Kaas, 1971) and CO (Tootell et al., 1985). In sections cut from the flattened cortex, the density of myelin in MT is unevenly distributed in a mottled pattern that suggests a modular organization (Fig. 2; Krubitzer and Kaas, 1990a). $\mathrm{MT}_{\mathrm{C}}$ borders most or all of the portion of MT that represents the zero vertical meridian, and it is only absent from the rostral portion of MT devoted to peripheral vision (see Allman and Kaas, 1971). The distinction between $\mathrm{MT}_{\mathrm{C}}$ and bordering cortex was most obvious in wet brain sections, examined just after they were cut. In such preparations, densely myelinated regions of cortex are conspicuously lighter than other regions (see Tigges and Shantha, 1969), and MT stands out as a pale oval with sharp boundaries. $\mathrm{MT}_{\mathrm{C}}$ is also apparent as a series of roughly 10-15 patches of dense myelin, bordering MT like beads and sometimes fusing with the MT border. These patches of myelinated cortex are less dense than MT, and they are embedded in a matrix of lighter myelination. Figure 1 is a drawing of such a section, and it most accurately shows the sizes and locations of the dense patches. In our sections processed for myelin, we were limited by the need to reserve sections for HRP and $\mathrm{CO}$ procedures. In addition, processing the sections resulted in some unevenness in the staining so that the borders of $\mathrm{MT}$ and the $\mathrm{MT}_{\mathrm{C}}$ patches were never as obvious as in the fresh sections. Nevertheless, the border of MT and some of the patches of $\mathrm{MT}_{\mathrm{C}}$ were apparent (Fig. 2). In the stained material, the $\mathrm{MT}_{\mathrm{C}}$ patches often appeared to be separated from the MT border by the matrix of lighter myelination.

Previously, Tootell et al. (1985) described the pattern of CO staining in sections from flattened cortex in owl monkeys, and noted both the dense CO staining of MT (also see Krubitzer and Kaas, 1990a) and the presence of an "arc" or "ring" of COdense patches along the caudal border of MT. Our material also revealed the CO-dense patches along the border of MT that identify $\mathrm{MT}_{\mathrm{C}}$. However, as for the myelin-stained sections, only some of the patches were apparent in any section (Fig. 3). 


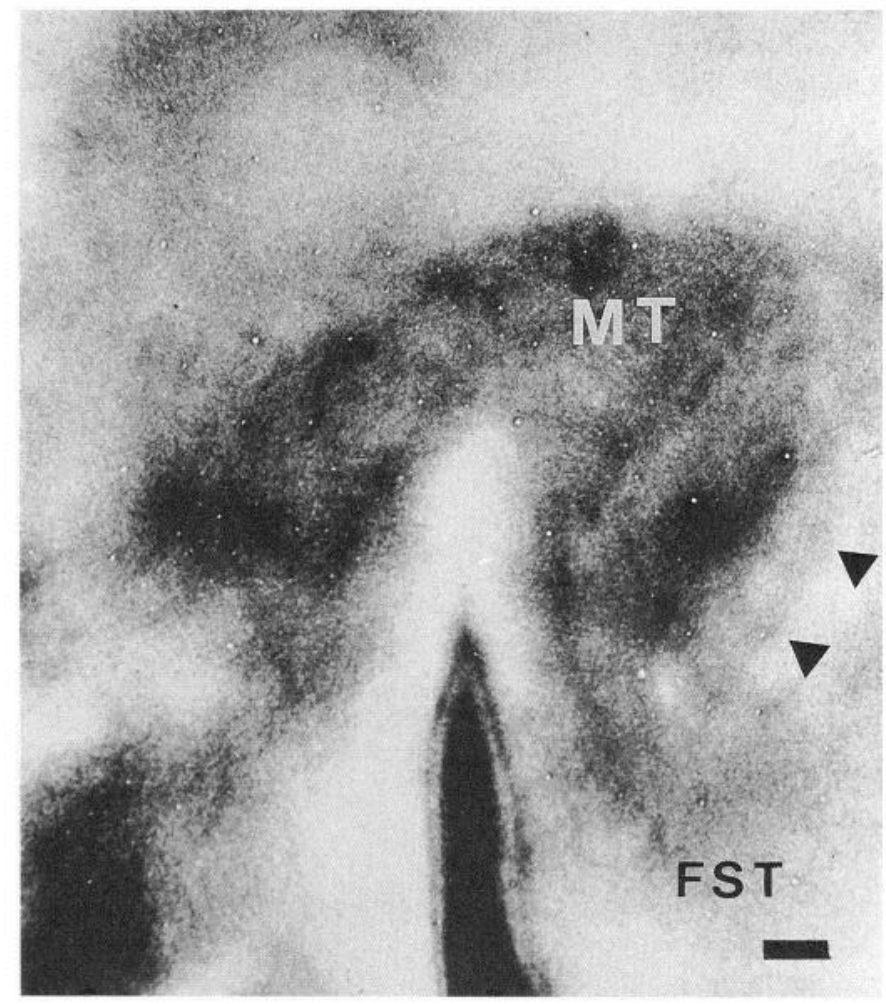

Figure 2. A photomicrograph of a brain section stained for myelin. $M T$ appears as a somewhat heterogenous, but densely myelinated field. Two of the myelinated patches of the $\mathrm{MT}_{\mathrm{C}}$ are marked with triangles. Part of FST is seen as a region of moderate myelination. Myelination within fields varies in the section, in part because cortical layers differ in myelin and the section is not all at the same depth, particularly in the region of the STS. The STS is just left of FST. See Figure 4 for orientation. Scale bar, $500 \mu \mathrm{m}$.
$\mathrm{FST}_{\mathrm{D}}$ and $\mathrm{FST}_{\mathrm{v}}$ are divisions of a region of moderately dense myelination that extends ventrally from MT along the lower bank of the STS(Figs. 1, 2). The region includes cortex extending somewhat on the surface of the temporal lobe. In sections from flattened cortex, the border of FST in the depths of the sulcus is difficult to determine because the sulcus induces an unevenness in the plane of section, and there may be problems in accurately locating this and other borders of FST. We noted no consistent difference between $\mathrm{FST}_{\mathrm{v}}$ and $\mathrm{FST}_{\mathrm{D}}$ in myelin preparations, but $\mathrm{FST}_{\mathrm{v}}$ sometimes appeared to be less dark. CO stains did not usefully delimit the fields.

\section{Connections of FST}

Injections placed in $\mathrm{FST}_{\mathrm{D}}$ produced a pattern of label that was quite different from that produced by injections placed in $\mathrm{FST}_{\mathrm{v}}$. Figures 4 and 5 show results from a case where the injection was centered in $\mathrm{FST}_{\mathrm{D}}$. The most significant observation was that patches of label were broadly distributed across MT, and no label was detected in $\mathrm{MT}_{\mathrm{C}}$. This difference is evidence that $\mathrm{MT}_{\mathrm{C}}$ is not functionally part of MT. In addition, the patchy distribution of label over most of MT indicates that FST $_{\mathrm{D}}$, as identified by connections, is probably not much larger than the injection site. Since MT forms a complete representation of the contralateral visual hemifield (e.g., Allman and Kaas, 1971), the interconnections of $\mathrm{FST}_{\mathrm{D}}$ with all portions of MT provide evidence that the cortex included in the injection site represents most of the visual hemifield. Such data, together with the architectonic results, suggest that FST $_{D}$ is about $8 \mathrm{~mm}^{2}$ in surface area.

The patches of label in MT and other regions contained both labeled neurons and fine neural processes. The labeled neurons indicate that neurons in MT and other regions of cortex project to $\mathrm{FST}_{\mathrm{D}}$, and the labeled processes, thought to be terminal arbors of inputs, suggest that $\mathrm{FST}_{\mathrm{D}}$ projects back to the same fields. The observation that label is concentrated in distributed patches
Figure 3. A photomicrograph of a brain section stained for CO. MT is apparent as a dark oval. Patches of dark $\mathrm{CO}$ staining corresponding to part of $\mathrm{MT}_{\mathrm{C}}$ are marked with triangles dorsal and caudal to MT. The STS is in the lower left. See Figure 4 for orientation. Scale bar, $500 \mu \mathrm{m}$.

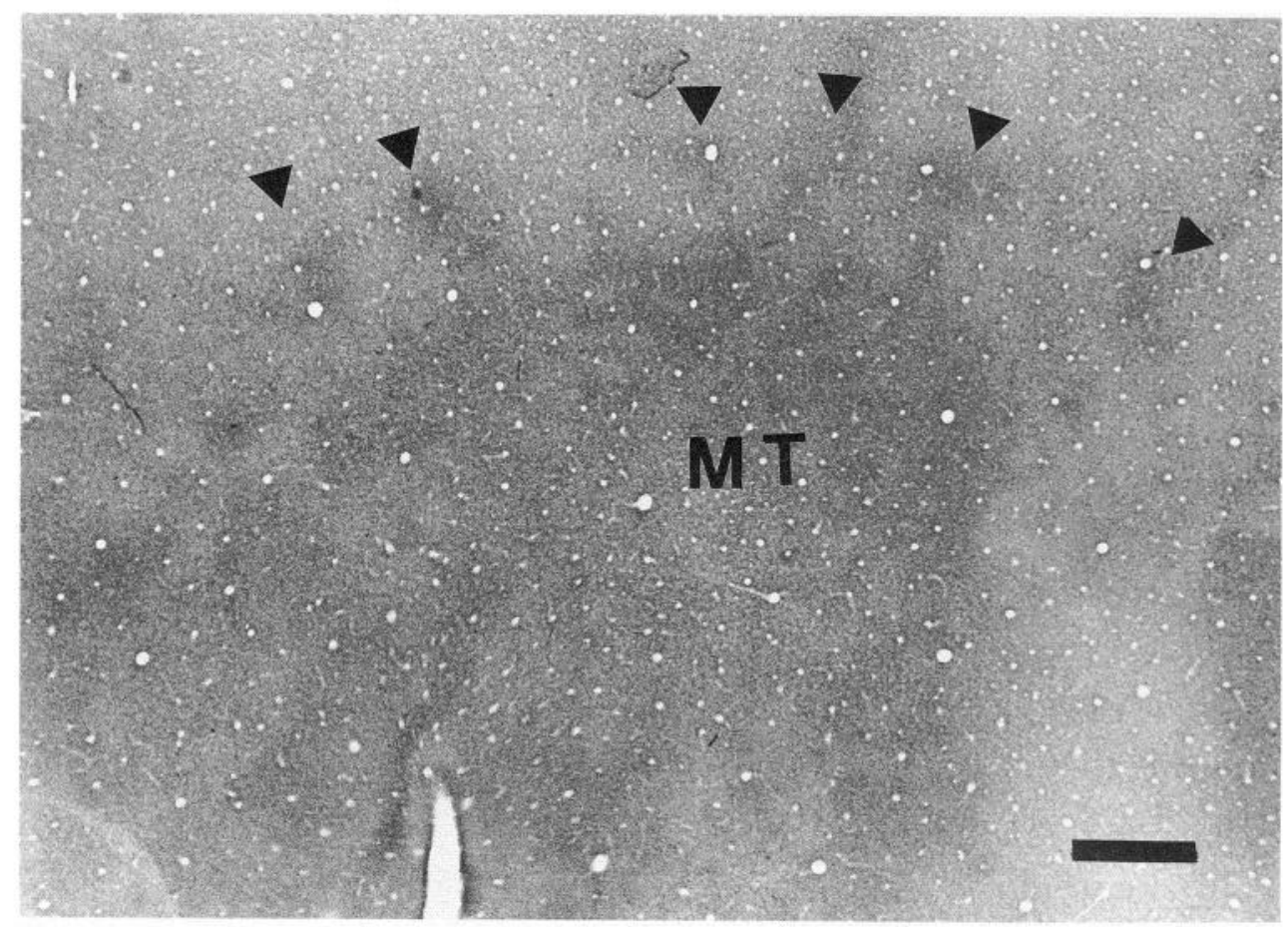




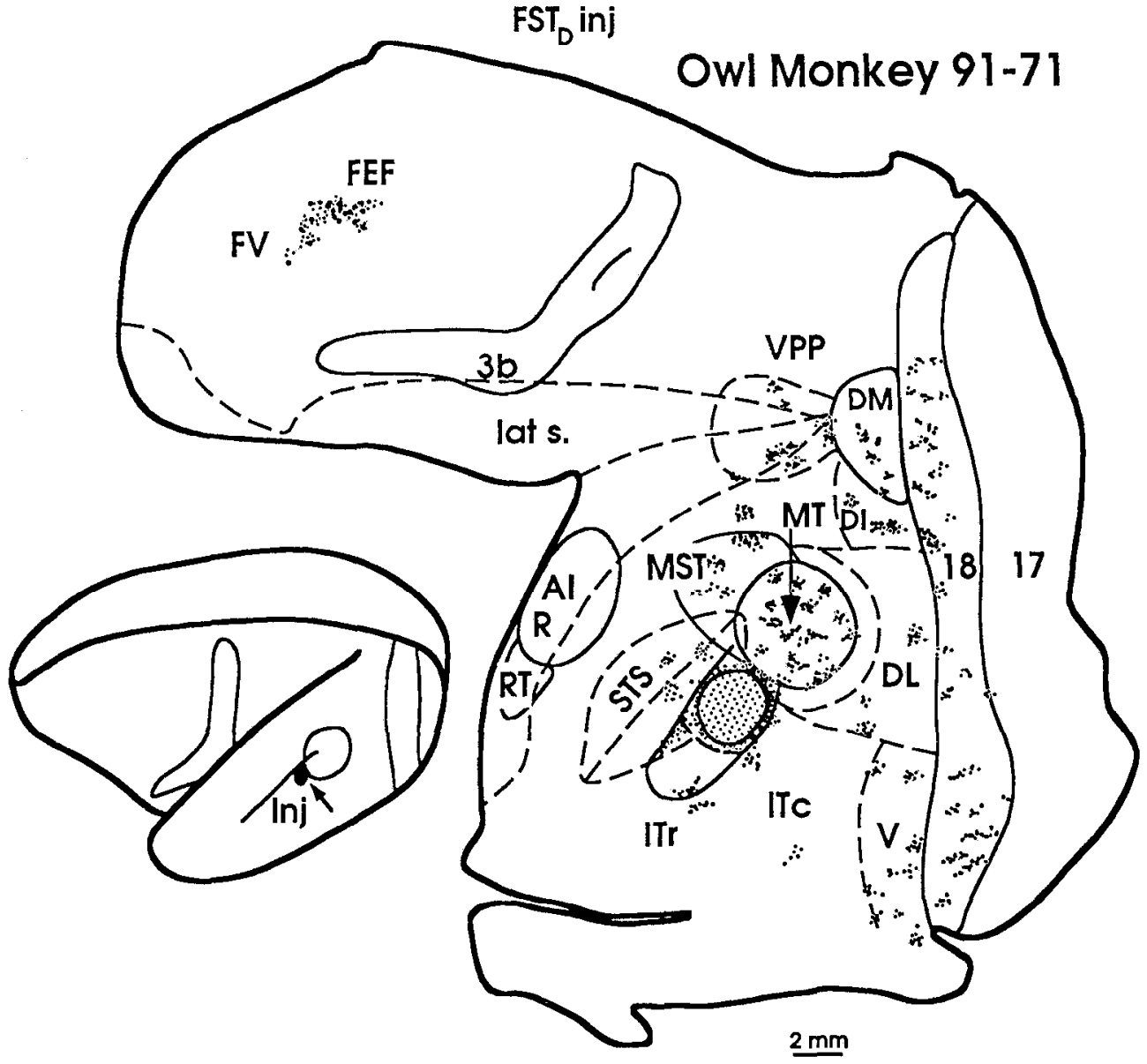

Figure 4. The distribution of label after an injection in $\mathrm{FST}_{\mathrm{D}}$. The inset drawing on the lower left shows a dorsolateral view of an owl monkey brain, with an arrow pointing to the injection site $(I n j)$. Boundaries of area $3 \mathrm{~b}$ of somatosensory cortex, area 18 (or V2), and $\mathrm{MT}$ are indicated for reference. The drawing on the right is from a single brain section cut parallel to the surface of manually flattened cortex. Results from adjacent sections are superimposed. The injection site of WGA-HRP is shaded. Labcled neurons and fine processes are indicated by large and small dots, respectively. Cortical areas outlined by solid lines were identified by myeloarchitecture; the locations of other areas were estimated (broken lines). No architectonic border was distinguished between $\mathrm{FST}_{\mathrm{D}}$ and $\mathrm{FST}_{\mathrm{v}}$, and the broken line only indicates a probable border deduced from connection patterns. Broken lines also indicate the extents of cortex buried in the lateral sulcus (lat s.) and the STS. Visual areas (see Krubitzer and Kaas, 1990a) include areas 17 (V1) and 18 (V2), DL, DI, DM, the ventral or ventroposterior area $(V)$, rostral $(I T r)$ and caudal $(I T c)$ areas of IT cortex, $\mathrm{FST}_{\mathrm{D}}$ and $\mathrm{FST}_{\mathrm{v}}$, MT, MST, and VPP. FEF and FV are visuomotor fields. Auditory areas include $A I$ or primary auditory cortex; $R$, the rostral field; and $R T$, as the rostrotemporal field (see Morel and Kaas, 1992). in MT and other fields suggests that all thesc fields are modularly organized.

MT and three other targets of FST $_{D}$ are of special interest because they are key structures in a "dorsal stream" of visual processing that is thought to be important in visual attention, tracking, and spatial vision (Ungerleider and Mishkin, 1982). MST, DM, and VPP are all interconnected with MT and with each other as part of this stream (Weller et al., 1984; Krubitzer and Kaas, 1990a,b). The connections of FST ${ }_{D}$ with MST, DM, and VPP, as well as MT, clearly associate $\mathrm{FST}_{\mathrm{\nu}}$, with the dorsal stream.

A somewhat unexpected finding was that area 18 has direct connections with FST $_{D}$. The distribution of patches of label over most of area 18 in case $91-71$ (Figs. 4,6 ) is consistent with the conclusion that the injection included most of the visual hemifield representation in $\mathrm{FST}_{\mathrm{D}}$, since area 18 systematically represents the contralateral visual hemificld (Allman and Kaas, 1974a). Patches of label were present in both dorsomedial area 18 , which represents the lower visual quadrant, and ventrolateral area 18, which is devoted to the upper visual quadrant. Label in area 18 largely overlapped the CO-dense bands that characterize the field (e.g., Tootell et al., 1985). Sets of alternating bands in area 18 of owl monkeys project to either MT (Weller el al., 1984; Krubitzer and Kaas, 1990a,b) or DL (Krubitzer and Kaas, 1990a) as in other primates, but unlike macaques (e.g., DeYoe and Van Essen, 1988; Livingstone and $\mathrm{Hu}$ bel, 1988), the bands projecting to MT in owl monkeys are not notably thicker than the other set. Thus, it is uncertain from the present material if the same bands in area 18 that project to MT also project to $\mathrm{FST}_{\mathrm{D}}$, as might be expected by the association of $\mathrm{FST}_{\mathrm{D}}$ with the dorsal stream. Moreover, it appears from the arrangement of label that adjacent dark bands sometimes connect with $\mathrm{FST}_{\mathrm{D}}$, suggesting that both sets of bands contribute to $\mathrm{FST}_{\mathrm{D}}$. Other regions of label include the ventral (or ventral posterior) area (Newsome and Allman, 1980; Newsome et al., 1986), a region that appears to be associated with the ventral stream in macaque monkeys due to the presence of a significant proportion of neurons involved in color processing (Burkhalter and Van Essen, 1986), as well as locations in the inferior temporal (IT) lobe, cortex deep in the STS, and the dorsointermediate area, DI. Additional foci of label appear to be in the FEF and the frontal visual area (FV).

Interhemispheric connections were also revealed by the injections in FST $_{D}$. Results from case 91-71 are shown in Figure 7. Patches of labeled neurons and fine processes were found in $\mathrm{FST}_{\mathrm{D}}, \mathrm{MT}$, MST, and IT cortex. The densest label was in $\mathrm{FST}_{\mathrm{D}}$, where one large patch and several smaller patches were obvious. Other patches of label were scattered over MT, a few were within or above MST, and one was in IT cortex. Since MT, MST and FST all represent the contralateral hemifield (e.g., Desimone and Ungerleider, 1986), most of the interhemispheric connections appear to be between neurons with excitatory receptive ficlds in different visual hemificlds.

\section{Connections of $F S T_{V}$}

Injections centered about $3 \mathrm{~mm}$ ventral to the border of MT on the lip of the STS produced a quite different pattern of connec- 


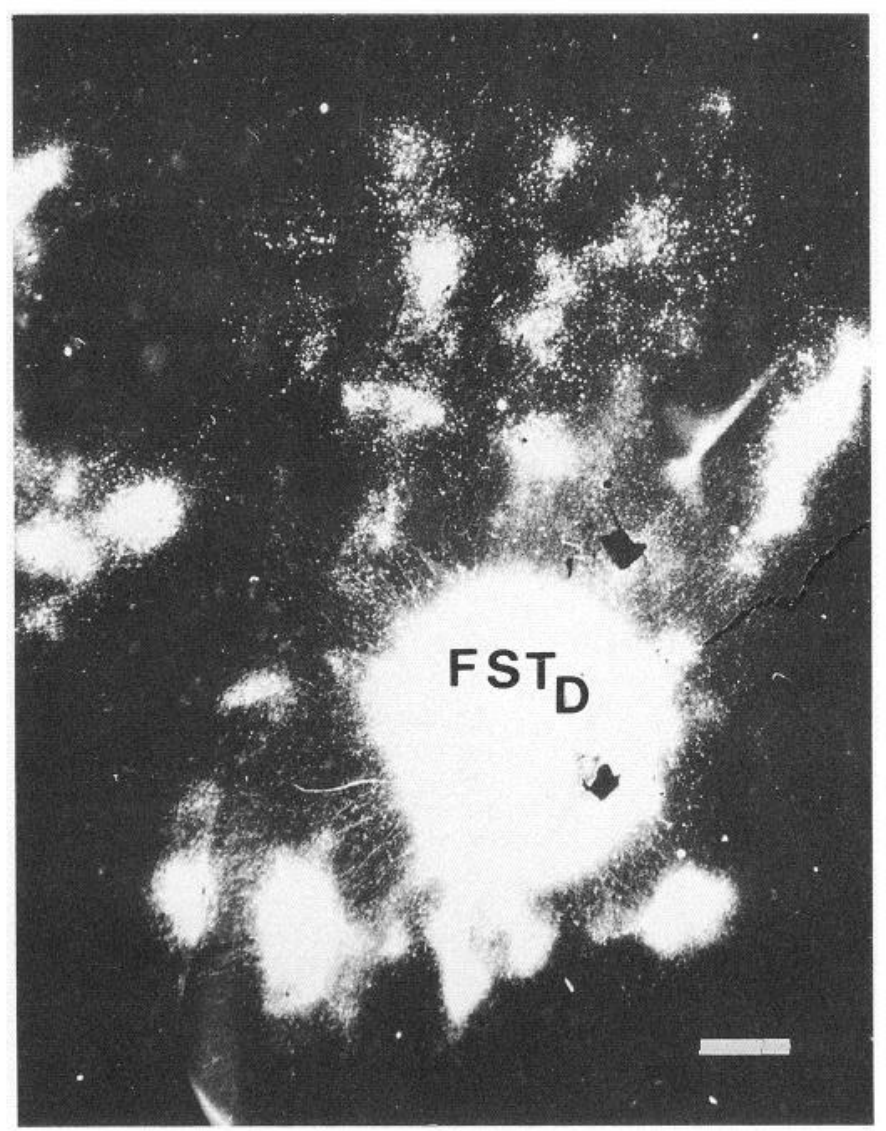

Figure 5. A dark-field photomicrograph of an injection site of WGAHRP in FST ${ }_{D}$ and the resulting label in MT, MST, FST ${ }_{v}$, and IT. Case 91-71; compare with Figure 4 for orientation. Scale bar, $500 \mu \mathrm{m}$.

tions than more dorsal injections. The results distinguish $\mathrm{FST}_{\mathrm{v}}$ from FST $_{\mathrm{D}}$. The most notable features of the different pattern were the total lack of label in MT, and the array of dense patches of label in $\mathrm{MT}_{\mathrm{C}}$ (Figs. 8, 9). Where CO-dense patches were apparent in $\mathrm{MT}_{C}$, these foci of label overlapped the CO-dense patches. Other differences were that no foci of label were in MST or in VPP, and only sparse amounts of label were in DM. Thus, the connection pattern did not associate $\mathrm{FST}_{\mathrm{v}}$ with areas of the dorsal stream of visual processing. Instead, major connections were with IT cortex, largely in numerous locations in the caudal division, $\mathrm{IT}_{\mathrm{C}}$, but also more ventrally near or in the rostral division, $\mathrm{IT}_{\mathrm{R}}$ (Weller and Kaas, 1987; Weller and Steele, in press). Additional foci of labeled neurons and processes were in FST $_{\mathrm{D}}$, adjacent cortex in the STS, the lateral and medial parts of DL, and in middle parts of area 18. The label in area 18 appeared to be largely within the $\mathrm{CO}$-dense bands. In the frontal lobe, both FEF and FV had dense amounts of label, as after $\mathrm{FST}_{\mathrm{D}}$ injections, but unlike the $\mathrm{FST}_{\mathrm{D}}$ cases, there also was a small focus of label in the region of the eye movement portion of the supplementary motor area (see Gould et al., 1986; Huerta and Kaas, 1990), also known as the supplementary eye field. While the overall significance of the pattern is not completely clear, the major connections with $\mathrm{IT}_{C}$ and $\mathrm{IT}_{\mathrm{R}}$ seem to associate FST $_{\mathrm{v}}$ with the ventral stream of visual processing (Ungerleider and Mishkin, 1982).

Injections of $\mathrm{FST}_{\mathrm{v}}$ also labeled fibers in several locations in the contralateral temporal cortex. Results for case 91-64 are

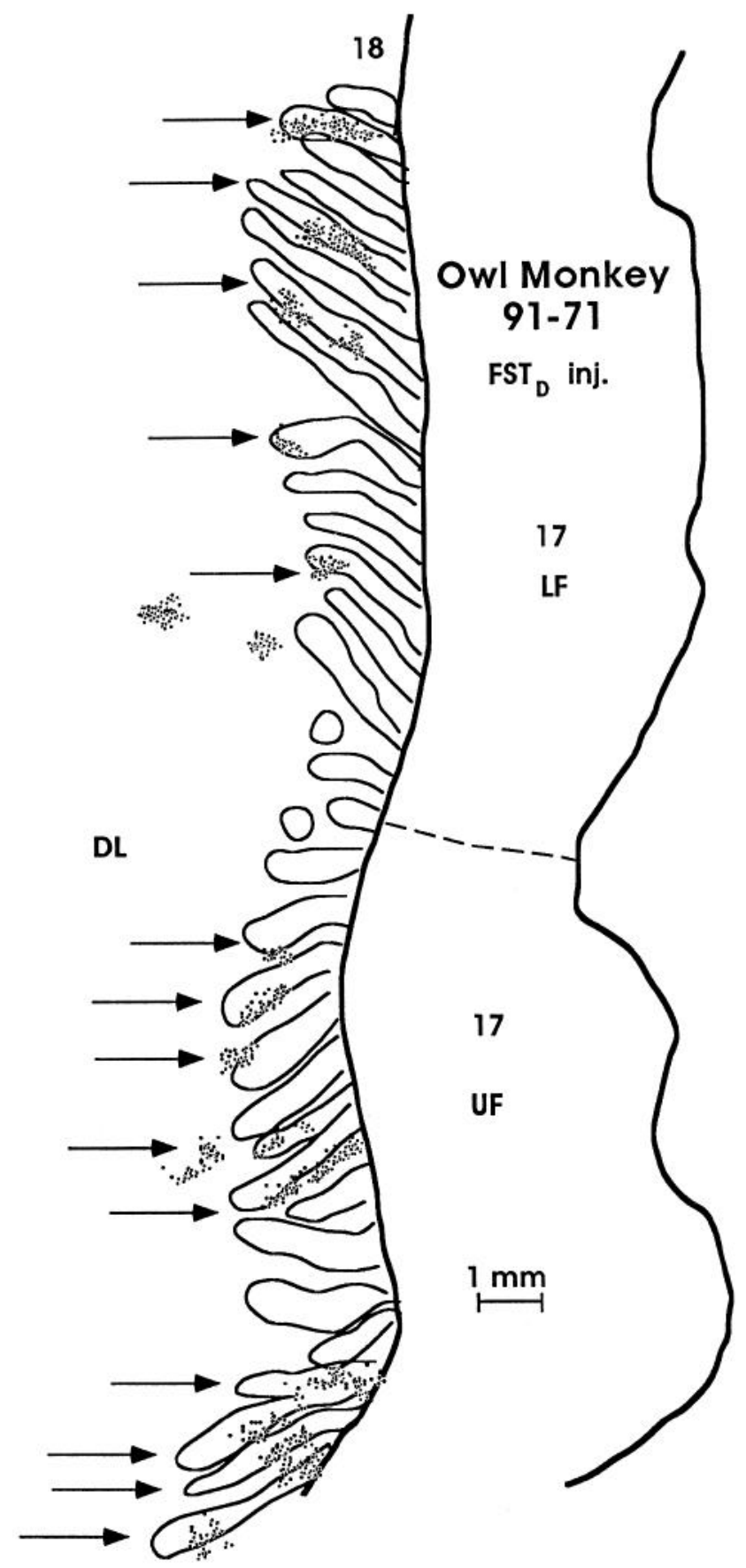

Figure 6. The distribution of label in area 18 (V2) after an injection of HRP-WGA into FST ${ }_{\mathrm{D}}$. The CO-dense bands in area 18 are outlined. Much of the label was in the bands, which are not easily classified as thick or thin in owl monkeys. A broken line separates the representations of the lower visual field $(L F)$ from the upper visual field $(U F)$ in area 17. Arrows point to 14 bands with label. Note that the labeled portion, which includes much but not all of area 18, extends over a span of 30 bands.

shown in Figure 10. As expected, the most dense label was in $\mathrm{FST}_{\mathrm{v}}$. Other foci of label were scattered in $\mathrm{FST}_{\mathrm{D}}$ and $\mathrm{MT}_{\mathrm{C}}$. No label was in MT or MST. Thus, FST $_{v}$ of one hemisphere has connections with $\mathrm{FST}_{\mathrm{v}}, \mathrm{FST}_{\mathrm{D}}$, and $\mathrm{MT}_{\mathrm{C}}$ of the other hemisphere. $\mathrm{FST}_{\mathrm{D}}$ and $\mathrm{MT}_{\mathrm{C}}$ are also targets of the ipsilateral projections of FST $_{\mathrm{v}}$. 


\section{Owl Monkey \\ 91-71}

\section{Contra FST $_{D}$ inj. WGA-HRP}

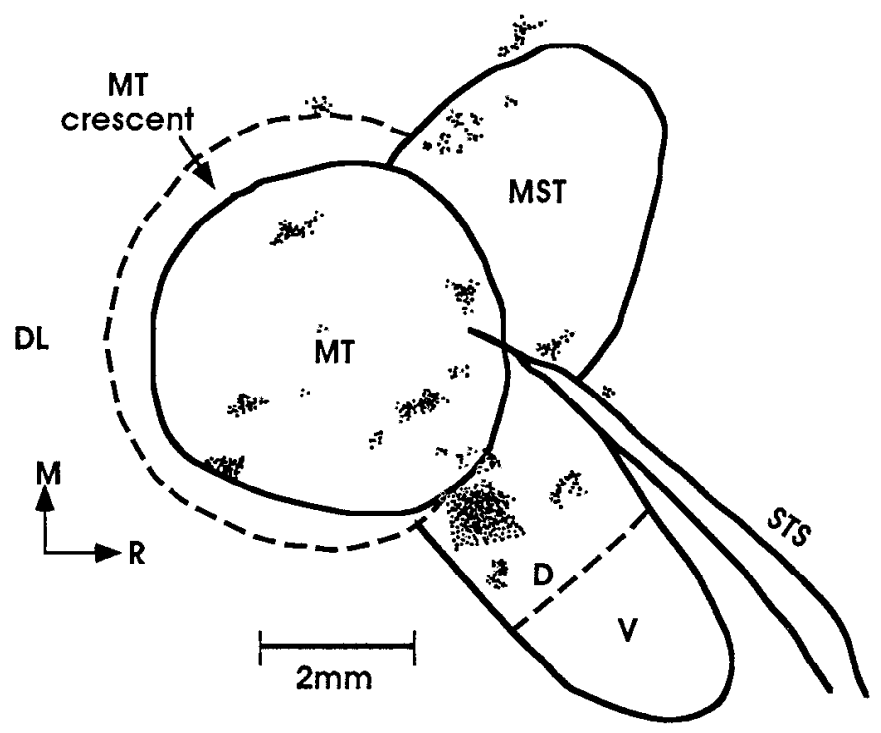

Figure 7. The distribution of label after an injection of WGA-HRP in FST $_{D}$ of the opposite hemisphere. Labeled neurons and processes were in $\operatorname{FST}_{\mathrm{D}}(D)$ rather than $\operatorname{FST}_{\mathrm{v}}(V)$, and in MT and MST. Conventions are as in Figure 4.

\section{Supporting evidence from other cases}

Results from cases 91-71 and 91-64 were very compelling because the patterns of connections were so different. Most notably, foci of label were scattered over most of MT and totally lacking in $\mathrm{MT}_{C}$ in case 91-71 where $\mathrm{FST}_{\mathrm{D}}$ was injected, while the opposite pattern occurred in case 91-64 where FST $_{\mathrm{v}}$ was injected. Results from other cases were less clear because injections appeared by location to involve less of either $\mathrm{FST}_{\mathrm{D}}$ or $\mathrm{FST}_{\mathrm{V}}$, and they typically included parts of both fields or parts of other adjacent fields. We describe results from four such cases. In addition, we describe one case where injections were placed in $\mathrm{MT}_{\mathrm{C}}$ and $\mathrm{MT}$.

Figure 11 illustrates results from case 91-79 where an injection appeared to straddle the border between $\mathrm{FST}_{\mathrm{D}}$ and $\mathrm{FST}_{\mathrm{v}}$. The injection was centered about $2 \mathrm{~mm}$ ventral to the border of MT. Patches of label were observed in MT, MST, DM, and VPP, as after a $\mathrm{FST}_{\mathrm{v}}$ injection, but other patches of label were in $\mathrm{MT}_{\mathrm{c}}$ and in IT cortex, as after an FST $\mathrm{v}$ injection. Other foci of label in area 18, DL, DI, FEF, and FV are characteristic of both $\mathrm{FST}_{\mathrm{D}}$ and $\mathrm{FST}_{\mathrm{v}}$ injections. Patches of label were distributed over caudal MT and middle $\mathrm{MT}_{\mathrm{C}}$. Since these regions represent central and paracentral vision rather than peripheral vision (Allman and Kaas, 1971, 1974b; Sereno and Allman, 1991), the border region between $\mathrm{FST}_{\mathrm{D}}$ and $\mathrm{FST}_{\mathrm{V}}$ appears to be also devoted to central and paracentral vision. Foci of label in DL and area 18 are also in parts representing central and paracentral vision (Allman and Kaas, 1974a,b).

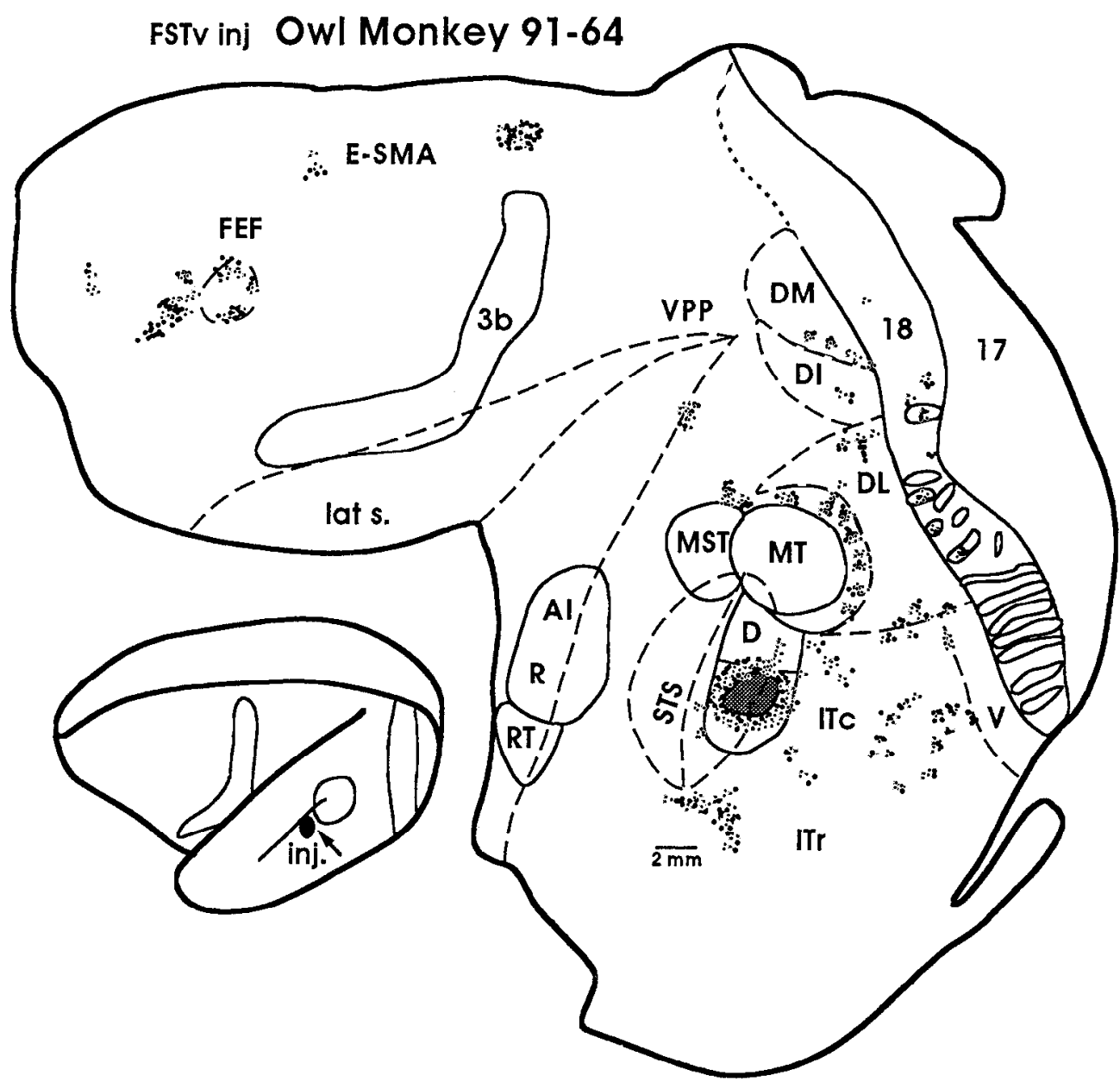

Figure 8. The distribution of label after an injection of WGA-HRP in FST $_{\mathrm{v}}$. Patches of label are in $\mathrm{MT}_{C}$ and are not in MT. E-SMA, eye movement part of the supplementary motor area. Conventions are as in Figure 4. 


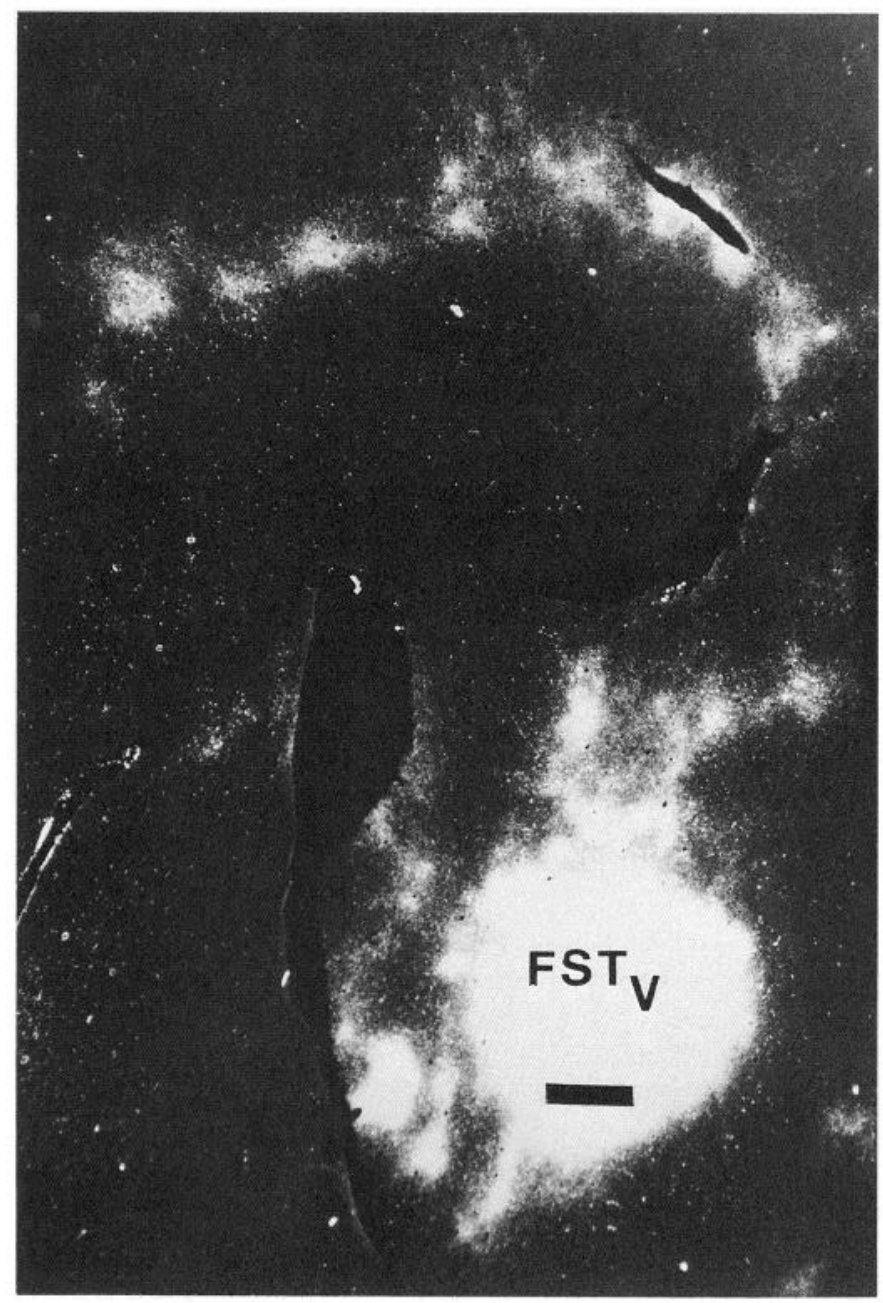

Figure 9. A dark-field photomicrograph of an injection site in $\mathrm{FST}_{\mathrm{v}}$ and transported label in $\mathrm{MT}_{\mathrm{C}}$. Case 91-64. Compare with Figure 8 for orientation. Scale bar, $500 \mu \mathrm{m}$.

Figure 12 shows the distribution of label after a small injection in $\mathrm{FST}_{\mathrm{v}}$ along its caudal border. This smaller injection resulted in less transported label than in other cases, and there appeared to be no involvement of $\mathrm{FST}_{\mathrm{D}}$, since no label was located in MT. Thus, the ventral border of $F_{S T}$ is not much over $2 \mathrm{~mm}$ from the border of MT. The injection also appeared to involve $\mathrm{FST}_{\mathrm{v}}$ only minimally, since only two foci of label were in $\mathrm{MT}_{\mathrm{c}}$. The distribution of foci of label over IT cortex is characteristic of $\mathrm{FST}_{\mathrm{v}}$ injections, but the label in MST is not. Possibly the extension of the injection site into cortex caudal to $\mathrm{FST}_{\mathrm{v}}$ (see Weller and Steele, in press) accounted for the label in MST. Other foci of label were in FV and FEF, as after either FST ${ }_{D}$ or $\mathrm{FST}_{\mathrm{v}}$ injections. The minimal involvement of FST $\mathrm{v}$ by the injection may explain the lack of detectable label in area $18, \mathrm{DM}$, and DI.

Results of two other cases (not illustrated) provide additional support for our conclusions that the FST region has dorsal and ventral subdivisions connecting with either $\mathrm{MT}$ or $\mathrm{MT}_{\mathrm{C}}$. In case 91-87, an injection of WGA-HRP was placed ventral to MT where it appeared to involve the border between $\mathrm{FST}_{\mathrm{v}}, \mathrm{FST}_{\mathrm{D}}$, and $\mathrm{IT}_{\mathrm{C}}$. The injection produced four foci of label in ventral $\mathrm{MT}_{\mathrm{C}}$, as well as foci in MT, MST, and locations in IT cortex. Thus, the results are similar to those illustrated for case 91-79

\section{Owl Monkey 91-64}

\section{Contra FST ${ }_{V}$ inj. WGA-HRP}

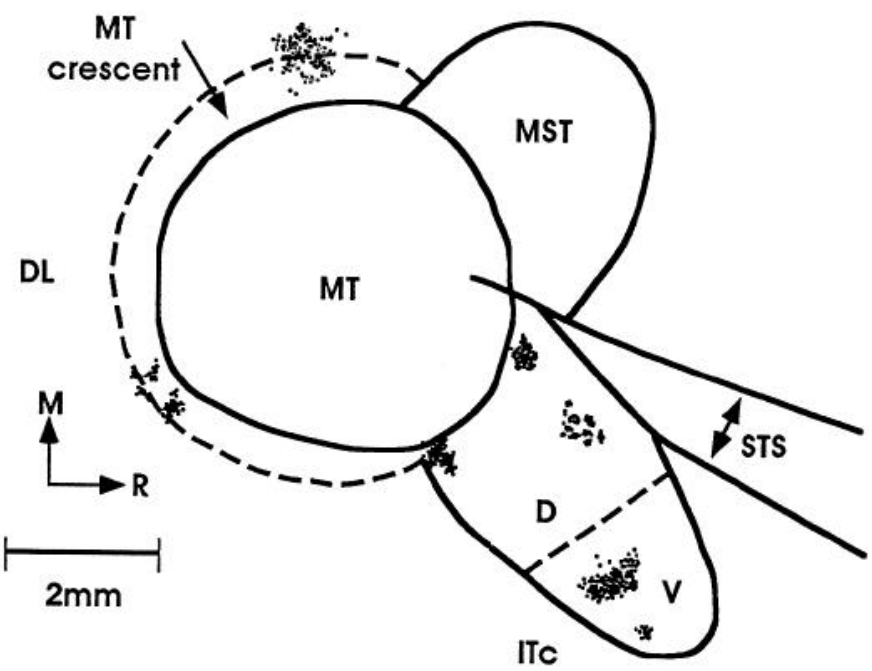

Figure 10. The distribution of label after an injection of WGA-HRP into $\mathrm{FST}_{\mathrm{v}}$ of the contralateral hemisphere. Note label in both $\mathrm{FST}_{\mathrm{v}}(V)$ and $\mathrm{FST}_{\mathrm{D}}(D)$, and in $\mathrm{MT}_{\mathrm{C}}$. Compare with Figure 7. Conventions are as in Figure 4.

(Fig. 11), except that the labeled zones in $\mathrm{MT}_{\mathrm{C}}$ were more ventral, the label in MT was more caudoventral, and there was less label in both MST and MT. In another case, two adjacent injections of Fluoro-Ruby were placed in cortex just ventral to MT. Again, the size and location of the merged injection sites suggested that $\mathrm{FST}_{\mathrm{v}}, \mathrm{FST}_{\mathrm{D}}$, and $\mathrm{IT}_{\mathrm{C}}$ were all involved. Labeled neurons were located in MT, $\mathrm{MT}_{c}$, MST, as well as other locations across visual cortex, including scattered sites in area 18.

In a final case (Fig. 13), we attempted to provide further evidence on the connections of $\mathrm{FST}_{\mathrm{D}}$ and $\mathrm{FST}_{\mathrm{v}}$ by injecting diamidino yellow in MT and fast blue and WGA-HRP in different locations in $\mathrm{MT}_{\mathrm{C}}$ of the same animal. The injection in MT labeled neurons in $\mathrm{FST}_{\mathrm{D}}$ and other fields known to project to MT, but no labeled neurons were present in $\mathrm{FST}_{\mathrm{v}}$. Thus, the results conform to our expectation that only $\mathrm{FST}_{\mathrm{D}}$ would have labeled neurons. The other two injections were successfully placed in $\mathrm{MT}_{\mathrm{c}}$, but given the narrowness of this strip of cortex, the injections were not completely confined to the field. Both injections also involved small parts of DL and MT. Both injections labeled neurons in $\mathrm{FST}_{\mathrm{D}}$ and $\mathrm{FST}_{\mathrm{v}}$. The label in $\mathrm{FST}_{\mathrm{v}}$ provides further evidence that $\mathrm{MT}_{\mathrm{C}}$ and $\mathrm{FST}_{\mathrm{v}}$ are interconnected, although the label possibly could result from the extensions of the injection sites into DL. Our injections in $\mathrm{FST}_{\mathrm{D}}$ and $\mathrm{FST}_{\mathrm{v}}$ only sparsely labeled $\mathrm{DL}$, but injections in rostral $\mathrm{DL}\left(\mathrm{DL}_{\mathrm{R}}\right)$ in squirrel monkeys are known to label the FST region (Steele et al., 1991).

\section{Discussion}

Results from an effort to determine the connections of FST in owl monkeys lead to two unanticipated conclusions. First, a region that we previously considered to be one field, FST, is 


\section{Owl Monkey 91-79 FSTV D \& V inj}

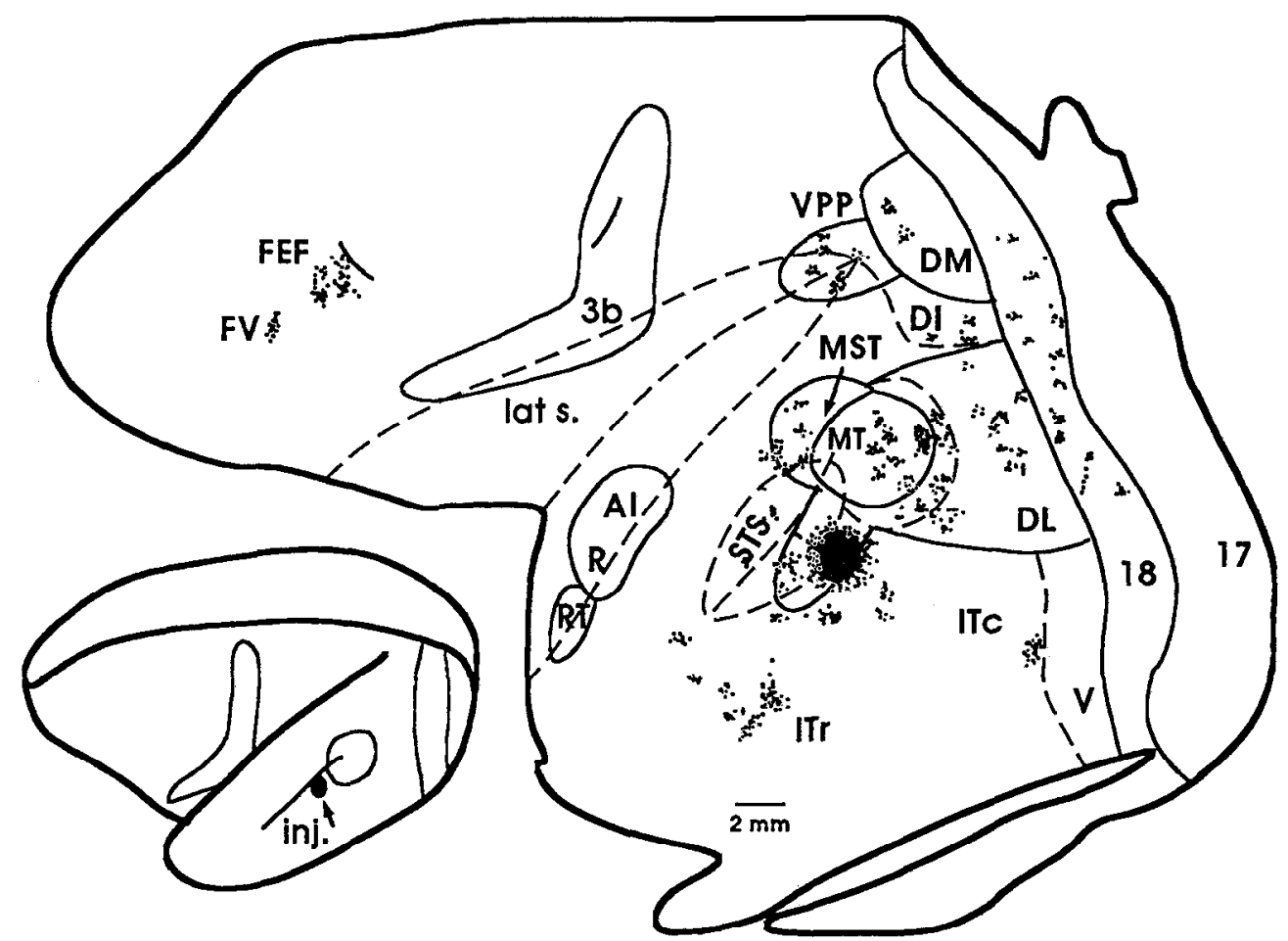

Figure 11. The distribution of label after an injection that involved both $\mathrm{FST}_{\mathrm{V}}$ and $\mathrm{FST}_{\mathrm{D}}$. Note label in both MT and $\mathrm{MT}_{\mathrm{C}}$. Conventions are as in Figure 4.

really two areas with quite different patterns of connections. The other conclusion is that a narrow crescent-shaped string of $\mathrm{CO}$ dense patches surrounding MT, previously described by Tootell et al. (1985), also is a complete visual area, termed here the
$\mathrm{MT}_{\mathrm{C}}$. The evidence suggests that each of these regions is a distinct processing unit for information across the visual field, with different inputs and outputs, and, by implication, populations of neurons with different responsc characteristics.

\section{Owl Monkey 91-76}

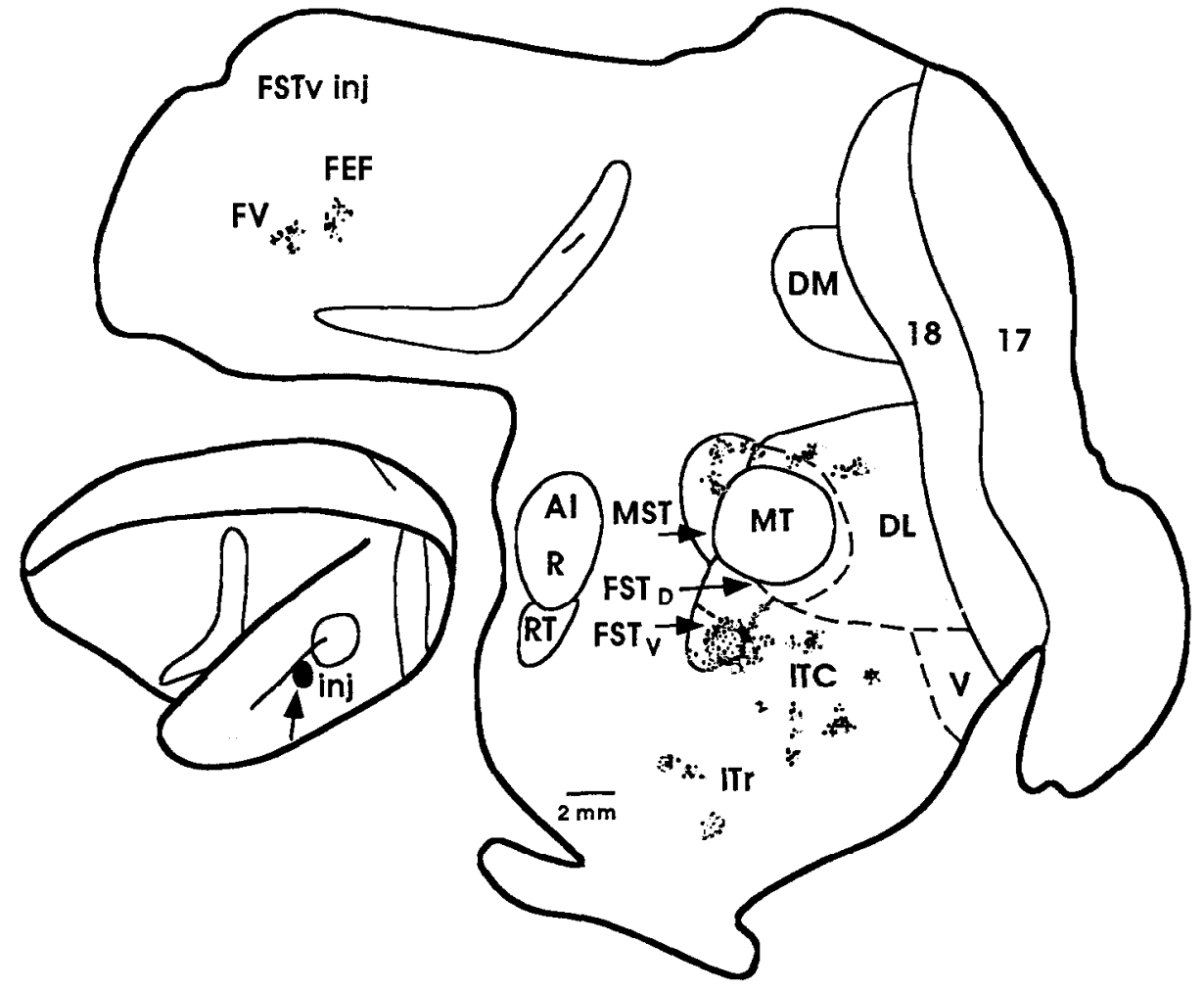

Figure 12. The distribution of label after an injection involving FST $_{\mathrm{v}}$ and $\mathrm{FST}_{\mathrm{D}}$. Only part of $\mathrm{MT}_{\mathrm{C}}$ is labeled. Conventions are as in Figure 4. 
Figure 13. Distributions of label after an injection of diamidino yellow (circled triangle) in MT and fast blue ( $F b$. circled dot) and WGA-HRP (stipple) in $\mathrm{MT}_{\mathrm{C}}$. All three injections involved $\mathrm{MT}$, and labeled neurons were found in FST $_{\mathrm{D}}$. However, only the fast blue and WGA-HRP injections also involved $\mathrm{MT}_{\mathrm{C}}$, and only these injections labeled neurons in $\mathrm{FST}_{\mathrm{v}}$. Conventions are as in previous figures.

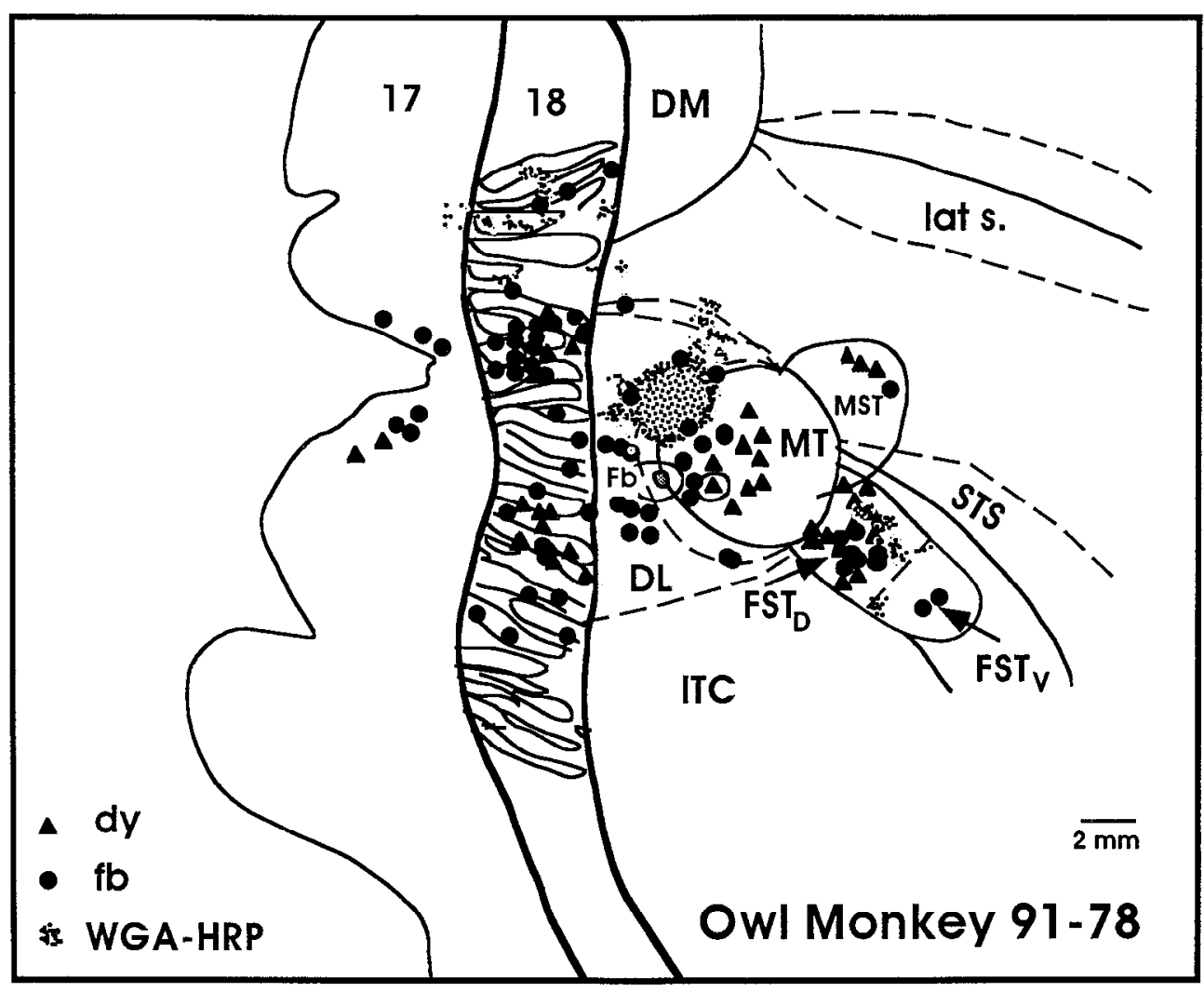

$F S T_{D}, F S T_{V}$, and $M T_{C}$ as visual areas

The present evidence on connection patterns argues that $\mathrm{FST}_{\mathrm{D}}$, $\mathrm{FST}_{\mathrm{v}}$, and $\mathrm{MT}_{\mathrm{C}}$ are separate visual areas. In concept, visual areas are subdivisions of visual cortex that transform inputs so that outputs differ from inputs (see Kaas, 1989). Areas differ from modules in that modules are compartments of visual areas that individually deal with information from limited parts of visual space, and only collectively mediate functions for all visual space (Kaas, 1990). The distinctively different connections of $\mathrm{FST}_{\mathrm{D}}, \mathrm{FST}_{\mathrm{V}}$, and $\mathrm{MT}_{\mathrm{C}}$ indicate that each of these regions is either an area or module of visual cortex. Modules or subfields within an area may differ in connections. For example, the parts of area 17 and MT that represent central vision have somewhat different connections than the parts representing peripheral vision (e.g., see Krubitzer and Kaas, 1990a). However, injections that include much of either $\mathrm{FST}_{\mathrm{D}}$ or $\mathrm{FST}_{\mathrm{v}}$ produce label over large extents of other previously established visual areas, providing evidence that each pair (one in each hemisphere) of these fields represents most or all of the visual field. Thus, each of these cortical regions appears to be an area rather than a module or subfield within an area (Kaas, 1990). Although $\mathrm{FST}_{\mathrm{D}}, \mathrm{FST}_{\mathrm{v}}$, and $\mathrm{MT}_{\mathrm{C}}$ seem small relative to areas such as 17 and 18 , they are not much smaller than MT and they are about the same size as other areas such as FEF (see Krubitzer and Kaas, 1990a).

As originally described in macaque monkeys, FST corresponds to a part of the projection zone of MT that has distinctive myeloarchitecture and extends rostroventrally from the rostroventral border of MT (Desimone and Ungerleider, 1986; Ungerleider and Desimone, 1986b). Using the criteria of moderately dense myelination and projections from MT, an FST was identified later in owl monkeys, squirrel monkeys, mar- mosets, and galagos (Krubitzer and Kaas, 1990a). The present evidence that dorsal and ventral parts of FST have distinctly different patterns of connections, with only FST $_{D}$ having notable connections with MT, is why we have divided FST into two visual areas. Since no clear difference between the two fields was apparent in the sections stained for myelin or $\mathrm{CO}$, and thus no architectonic border between the fields has yet becn detected. it seems likely that FST of squirrel monkeys, marmosets, macaque monkeys, and galagos contains dorsal and ventral visual areas. In all these primates, FST has been described as an elongated field, which, by location, would include $\mathrm{FST}_{\mathrm{D}}$ and $\mathrm{FST}_{\mathrm{V}}$. In addition, injections centered in MT typically produce foci of label largely or exclusively in the dorsal part of FST, while injections in MT that are near the border, and include or possibly include parts of $\mathrm{MT}_{\mathrm{C}}$, tend to label both dorsal and ventral locations in FST (Maunsell and Van Essen, 1983; Weller et al., 1984; Desimone and Ungerleider, 1986; Ungerleider and Desimone 1986b; Krubitzer and Kaas, 1990a). Thus, the elongated field considered to be FST in macaque monkeys (Ungerleider and Desimone 1986b) and in various new-world monkeys and prosimian primates (Krubitzer and Kaas, 1990a) may contain two visual areas, as in owl monkeys. In galagos, Preuss and Goldman-Rakic (1991) architectonically identified an FST that corresponds closely in size and location to the present $\mathrm{FST}_{\mathrm{D} \text { - }}$

$\mathrm{MT}_{C}$ is a narrow field that borders most of MT. MT $\mathrm{M}_{C}$ is characterized by a number of closely spaced patches of CO- or myelin-dense tissue separated by narrow surrounds of light-staining tissue, much like the barrels and matrix of somatosensory cortex of rats (e.g., Dawson and Killackey, 1987). This internal structure was most obvious in the myelin pattern seen in freshly cut, wet brain sections, which often show patterns of myelination more clearly than stained sections (e.g., Tigges and Shantha, 
1969). The pattern was also apparent in stained sections, though less complete and sharply defined. The present $\mathrm{MT}_{\mathrm{C}}$ appears to correspond to the palchy ring of CO-dark reaction product surrounding caudal MT in the preparations of Tootell et al. (1985). In the present cases and those of Tootell et al. (1985), the dense patches varied in distinctiveness, both for different parts of the ring and across cases. However, the modularity of $\mathrm{MT}_{\mathrm{C}}$ was also revealed by the connection pattern with $\mathrm{FST}_{\mathrm{v}}$, since most of the label was coextensive with the $\mathrm{CO}$ - and myelin-dense patches. In addition, the connection pattern more clearly disclosed the full extent of $\mathrm{MT}_{\mathrm{C}}$ by labeling patches that were not obvious in stained sections.

The connectional pattern of $\mathrm{FST}_{\mathrm{v}}$ with $\mathrm{MT}_{\mathrm{C}}$ suggests that both fields represent most or all of the contralateral visual hemifield. The portion of MT bordered by $\mathrm{MT}_{\mathrm{C}}$ represents the region of the zero vertical meridian (Allman and Kaas, 1971) from peripheral vision in the upper visual field (rostroventrally) through central vision (caudally) to peripheral lower field vision (rostrodorsally). Recordings in the $\mathrm{MT}_{\mathrm{C}}$ region just outside $\mathrm{MT}$ (considered part of $\mathrm{DL}$ ) revealed a similar progression of representation from upper to lower vision with a sequence of ventral to dorsal recording sites (Allman and Kaas, 1974b), and receptive fields for neurons in the $\mathrm{MT}_{\mathrm{C}}$ region are large, often including $10^{\circ}$ or more of visual space. Thus, there is evidence that cortex in the region of $\mathrm{MT}_{\mathrm{C}}$ represents much of the visual hemifield, from peripheral vision in the upper field to peripheral vision in the lower field, but it is not clear from this early report if $\mathrm{MT}_{\mathrm{C}}$ represents temporal parts of the visual hemifield away from the zero vertical meridian. Other more recent electrophysiological evidence from owl monkeys, not yet published in detail, suggests that bordering cortex within less than $1 \mathrm{~mm}$ of MT does indeed represent much or all of the visual hemifield (Sereno et al., 1987; Sereno and Allman, 1991).

\section{Evidence of $F S T_{D}$ and $F S T_{V}$ connections from previous studies}

The major connections of FST $_{\mathrm{D}}$ in owl monkeys were with MT, MST, DM, VPP, ventral or ventroposterior area $(\mathrm{V})$, and area 18. Injections in $\mathrm{FST}_{\mathrm{D}}$ also labeled locations in superior temporal cortex, DL, DI, and visuomotor cortex of the frontal lobe. Many of these findings are congruent with results obtained from studies of the connections of other visual areas in owl monkeys and other primates. As noted above, the $\mathrm{FST}_{\mathrm{D}}$ region was labeled by injections in MT of owl monkeys, squirrel monkeys, marmosets, galagos, and macaque monkeys (Spatz and Tigges, 1972; Van Essen et al., 1981; Wall et al., 1982; Mansell and Van Essen, 1983; Weller et al., 1984; Ungerleider and Desimone, 1986b; Krubitzer and Kaas, 1990a). In most cases, the cortex labeled by $\mathrm{MT}$ injections did not extend ventrally into the $\mathrm{FST}_{\mathrm{v}}$ region, but some ventral foci of label were depicted in some cases, suggesting the possible inclusion of $\mathrm{MT}_{\mathrm{C}}$ in the injection site. $\mathrm{FST}_{\mathrm{D}}$ also has major connections with MST, DM, and VPP. Thus, as expected, injections in the MST region of owl monkeys (dorsal ST; Weller et al., 1984) and macaque monkeys (Boussaoud et al., 1990) labeled the FST $_{D}$ region. Earlier studies of DM (Wagor et al., 1975) and posterior parietal cortex (Kaas and Lin, 1977) in owl monkeys failed to reveal projections to FST $_{\mathrm{D}}$, but more recent studies of DM in owl monkeys (Krubitzer and Kaas, 1990b; L. A. Krubitzer and J. H. Kaas, unpublished observations) and the DM region in squirrel monkeys (Weller et al., 1991), using modern methods, provide evidence for such connections. In macaque monkeys, the connections of the equivalent region of cortex, termed V3 and V3a, have not been studied directly (see Burkhalter et al., 1986), but posterior parietal cortex has connections with the FST ${ }_{\mathrm{D}}$ region (Morel and Bullier, 1990; Baizer et al., 1991). After $\mathrm{FST}_{\mathrm{D}}$ injections in the present cases, labeled neurons and processes in area 18 were concentrated in the CO-dense bands, but it was not clear if the labeled bands were largely those projecting to MT, DL, or both (see Krubitzer and Kaas, 1989, 1990a). Descriptions of connections revealed by injections in area 18 in New World (Kaas and Lin, 1977; Cusick and Kaas, 1988) and Old World monkeys (Ungerleider and Desimonc, 1986a) do not include FST, but label reported to be in ventral MT (Cusick and Kaas, 1988) or ventral to MT (Ungerleider and Desimone, 1986a) could include FST $_{\mathrm{D}}$. Injections in FST $_{D}$ also labeled neurons in the ventral region, V (VP and VA; see Burkhalter and Van Essen, 1986; Burkhalter et al., 1986; Sereno and Allman, 1991), DL, DI, IT , $_{\text {, and cortex in }}$ the STS. The sparseness of most of these connections suggests that they are unlikely to be revealed by direct injections in these areas, and little is known about VP or VA connections (Felleman and Van Essen, 1991). Finally, other rather dense connections of FST $_{\mathrm{D}}$ were with frontal cortex in the region of the FEF and an adjoining frontal ventral visual area (FV; see Krubitzer and Kaas, 1990a). Injections in FEF of squirrel monkeys, owl monkeys, and macaque monkeys labeled neurons in several locations of visual cortex including cortex just ventral to MT in the FST region (Huerta et al., 1987).

Connections of $\mathrm{FST}_{\mathrm{V}}$ differed from those of $\mathrm{FST}_{\mathrm{D}}$ by strongly involving $\mathrm{MT}_{\mathrm{C}}$ and more strongly involving $\mathrm{IT}_{\mathrm{C}}$ and $\mathrm{IT}_{\mathrm{R}}$. In the present study we attempted to inject $\mathrm{MT}_{C}$, but failed to confine injection sites to the field (Fig. 13). Nevertheless, injections that included $\mathrm{MT}_{\mathrm{C}}$, along with MT and perhaps $\mathrm{DL}_{\mathrm{R}}$, labeled $\mathrm{FST}_{\mathrm{V}}$, as well as other areas. Similarly, larger injections in MT of macaque monkeys that extended into surrounding cortex labeled ventral portions of FST that could be $\mathrm{FST}_{\mathrm{v}}$ (Ungerleider and Desimone, 1986b). In owl monkeys and squirrel monkeys with $\mathrm{IT}_{\mathrm{C}}$ and $\mathrm{IT}_{\mathrm{R}}$ injections, labeled regions of cortex included the $\mathrm{FST}_{\mathrm{V}}$ region more clearly than the $\mathrm{FST}_{\mathrm{D}}$ region (Weller and Kaas, 1987; Weller and Steele, in press). In addition, after injections in dorsal $\mathrm{IT}_{C}$ of squirrel monkeys, in cortex that might include $\mathrm{FST}_{\mathrm{v}}$, label was absent in MT and dense in $\mathrm{IT}_{\mathrm{C}}$ and $\mathrm{IT}_{\mathrm{R}}$ (Weller and Steele, in press), characteristics of FST $_{\mathrm{V}}$ rather than $\mathrm{FST}_{\mathrm{D}}$ connection patterns in owl monkeys.

The most relevant comparison of present results are with those reported by Boussaoud et al. (1990) after injections in the FST region of macaque monkeys. Conclusions were based on five cases, and results were illustrated for two cases with injections just rostroventral to MT in locations that would appear to involve largely $\mathrm{FST}_{\mathrm{D}}$. Consistent with this assumption, dense foci of label were noted in MT, MST, the V3 complex (DM), and posterior parietal cortex of both cases. Thus, the major connections of $\mathrm{FST}_{\mathrm{D}}$ seem to be highly similar in owl and macaque monkeys. Other scattered foci in V4 (DI.) and IT cortex correspond to sparse connections in owl monkeys, but area 18 (V2) connections were not reported for macaques. The dense label found in the FEF region could refiect $\mathrm{FST}_{\mathrm{D}}$ or $\mathrm{FST}_{\mathrm{V}}$ connections of owl monkeys. However, some connections of FST in macaques were like those of $\mathrm{FST}_{\mathrm{v}}$ of owl monkeys. Most notably, cortex just outside of MT in the position of $\mathrm{MT}_{\mathrm{C}}$ (termed $\mathrm{V} 4 \mathrm{t}$; see below) was labeled in both cases. This result could occur if the injections in FST of macaques largely involved $\mathrm{FST}_{\mathrm{D}}$, but also slightly involved $\mathrm{FST}_{\mathrm{v}}$. If so, major features of 
visual cortex organization and connections are similar in owl and macaque monkeys.

Finally, as for $\mathrm{FST}_{\mathrm{D}}$ of owl monkeys, the callosal connections of FST of macaque monkeys were with FST, MT, and MST. Callosal connections of visual areas are typically between an area and its pair and two to three adjoining areas of the opposite hemisphere (see Cusick and Kaas, 1986).

Relation of $M T_{C}$ to V4t, dorsal zone, and $D L_{C}$

If $\mathrm{MT}_{\mathrm{C}}$ is an area common to other monkeys, parts of cortex in the $\mathrm{MT}_{\mathrm{C}}$ region have been included in other proposed fields. Desimone and Ungerleider (1986b) distinguished a V4t as cortex within V4, but "transitional" between V4 and MT. V4t was described as a 1-2 $\mathrm{mm}$ wide strip of cortex of light myelination that extended $10 \mathrm{~mm}$ or more along the caudal portion of MT that is devoted to the lower visual quadrant in macaque monkeys. Recordings in $\mathrm{V} 4 \mathrm{t}$ revealed neurons with relatively large receptive fields, and a retinotopic order paralleling that in MT along the representation of the lower visual quadrant. V4l was thought to represent at least most of the lower visual quadrant, with $\mathrm{V} 4 \mathrm{t}$ and MT separated by the representation of the vertical meridian and $\mathrm{V} 4 \mathrm{t}$ and $\mathrm{V} 4$ separated by the representation of the horizontal meridian. No representation of the upper visual quadrant was detected in $\mathrm{V} 4 \mathrm{t}$, but the possibility was not ruled out. However, V4t has come to be described as an area that represents only the lower visual quadrant (e.g., Boussaoud et al., 1990; Felleman and Van Essen, 1991).

Comparable findings have been reported by others. Gattass et al. (1988) described a highly similar V4t in macaques, and noted that data published by Schein et al. (1982) and Maguire and Baizer (1984) had previously suggested a V4t. In New World cebus monkeys, Fiorani et al. (1989) found a representation of much of the lower visual quadrant in a narrow $2 \mathrm{~mm}$ wide strip of tissue along the medial border of MT, but termed the area "dorsal zone" (DZ) because it differed from V4t of macaques by having denser myelination. Perhaps more significantly, Sereno et al. (1987) reconsidered the organization of the DL in owl monkeys, and proposed that the medial half contains three representations of the lower visual quadrant, the most rostral of which they called DL proper and compared to $\mathrm{V} 4 \mathrm{t}$ of macaque monkeys. However, in a recent review illustrating proposed visual areas in owl monkeys, Sereno and Allman (1991) illustrate a larger field, $\mathrm{DL}_{\mathrm{A}}$ (anterior) that corresponds closely to $\mathrm{MT}_{\mathrm{C}}$ in shape and extent, rather than a "DL proper." By extent, $\mathrm{DL}_{\mathrm{A}}$ would appear to represent both upper and lower quadrants.

In summary, the electrophysiological evidence suggests that both New World and Old World monkeys have a representation of at least much of the lower visual quadrant in a narrow strip of cortex along part of the border of MT. We suggest that these recordings reflect part of $\mathrm{MT}_{C}$, and that a complete or nearly complete representation of the contralateral visual field borders MT. Although many visual areas, such as MT in macaques (e.g., Gattass and Gross, 1981; Maunsell and Van Essen, 1987), may disproportionately represent the lower visual quadrant, one puzzles over the concept that visual areas exist that represent only the lower or only the upper visual quadrants, since this implies that some visual abilities can be performed only with stimuli in the lower or upper quadrants. Thus, our proposal that $\mathrm{MT}_{C}$, contains a complete representation not only is consistent with most of the available evidence across simian species, but also conforms to the experience and expectation that sensory representations are complete. We are uncertain why electrophysi- ological evidence for $\mathrm{MT}_{\mathrm{C}}$ in macaques and cebus monkeys is limited to part of the border of MT, but certainly not all parts of the border are equally accessible for exploration. Further, the folded position of MT in the STS of most species of monkeys may complicate the study of architectonics so that it is difficult to recognize parts of $\mathrm{MT}_{\mathrm{C}}$. In addition, $\mathrm{MT}_{\mathrm{C}}$ is not that distinct in most myelin preparations in owl monkeys, and it may vary in appearance in macaque and cebus monkeys. Finally, the heterogeneous, patchy appearance of $\mathrm{MT}_{\mathrm{C}}$ may contribute to problems of identification, especially in sections that only include small portions of $\mathrm{MT}_{\mathrm{C}}$.

\section{Connections of $M T_{C}$}

The present evidence indicates that all or most parts of $\mathrm{MT}_{\mathrm{C}}$ are interconnected with $\mathrm{FST}_{\mathrm{v}}$. Since $\mathrm{MT}_{\mathrm{C}}$ is so narrow, it is difficult to determine $\mathrm{MT}_{\mathrm{C}}$ connections by placing injections in the field, since injections would likely involve other fields or be so small that they would not effectively label sparse pathways. Yet, some information on $\mathrm{MT}_{\mathrm{C}}$ connections can be obtained from studies of the connections of other cortical areas. Our limited results from one injection of a fluorescent tracer confined to MT (Fig. 13) suggest that major connections of $\mathrm{MT}_{\mathrm{C}}$ are not with MT. However, Ungerleider and Desimone (1986b) described projections from MT to V4t. Furthermore, in earlier studies of MT projections in owl monkeys and other primates (Weller et al., 1984; Krubitzer and Kaas, 1990a), foci of terminations attributed to $\mathrm{DL}$ appear, by location, to be in $\mathrm{MT}_{\mathrm{C}}$ (see, e.g., Fig. $6 B$ of Krubitzer and Kaas, 1990a). Thus, there may well be connections between $\mathrm{MT}$ and $\mathrm{MT}_{\mathrm{C}}$.

Other areas that appear to connect with $\mathrm{MT}_{\mathrm{C}}$, judging from illustrated label along the outer border of MT after injections in other fields, include caudal DL (Steele et al., 1991) and cortex in the region of DM (Weller et al., 1991). There is also evidence from the report of Boussaoud et al. (1990) in macaque monkeys that MST projects to V4t, although this is not explicit in the summary diagram. Finally, Sousa et al. (1991) report that neurons in their DZ (see above) of cebus monkeys project to area 17.

\section{Modular organization in $M T$ and $M T_{C}$}

The scattered distribution of patches of labeled cortex within MT after $\mathrm{FST}_{\mathrm{D}}$ injections and within $\mathrm{MT}_{\mathrm{C}}$ after $\mathrm{FST}_{\mathrm{v}}$ injections is consistent with the view that many visual areas are subdivided into interdigitated territories that are occupied by two or more sets of processing modules differing in connections, neural properties, and, of course, function (see Kaas, 1982, 1990; DeYoe and Van Essen, 1988; Livingstone and Hubel, 1988). Although the nature of the modular organizations of V1 and V2 is well understood (e.g., DeYoe and Van Essen, 1988; Livingstone and Hubel, 1988), little is known about other visual areas, other than that connections related to restricted injection sitcs arc typically distributed in patches (e.g., Krubitzer and Kaas, 1990a). However, there is evidence for an arrangement of modules in MT that approximates the spacing of the patchy connections with FST. Albright et al. (1984) suggested that MT contains alternations of "axis-of-motion" columns of the order of 400-500 $\mathrm{mm}$ in diameter, but these dimensions are larger than the sizes of the patches of label. It would be surprising if only neurons specific to some axis of motion project to $\mathrm{FST}_{\mathrm{D}}$. As another possibility, Born and Tootell postulate sets of distributed subregions in MT, devoted to either global or local motion processing (Tootell and Born, 1991; Born and Tootell, 1992). Per- 
haps one class of such modules is selectively interconnected with FST $_{\mathrm{D}}$.

$\mathrm{MT}_{\mathrm{C}}$ also exhibits a pattern of connections that appears to reflect modules. As of yet, however, there is no information on how patches and matrix of $\mathrm{MT}_{\mathrm{C}}$ differ other than in appearance and connections with $\mathrm{FST}_{\mathrm{v}}$.

\section{References}

Albright TD, Desimone R, Gross CG (1984) Columnar organization of directionally selective cells in visual area MT of the macaque. J Neurophysiol 51:16-31.

Allman JM, Kaas JH (1971) A representation of the visual field in the caudal third of the middle temporal gyrus of the owl monkey (Aotus trivirgatus). Brain Res 31:85-105.

Allman JM, Kaas JH (1974a) The organization of the second visual area (VII) in the owl monkey: a second order transformation of the visual field. Brain Res 76:247-265.

Allman JM, Kaas JH (1974b) A crescent-shaped cortical visual area surrounding the middle temporal area (MT) in the owl monkey (Aotus trivirgatus). Brain Res 81:199-213.

Baizer JS, Ungerleider LG, Desimone R (1991) Organization of visual inputs to the inferior temporal and posterior parietal cortex in macaques. J Neurosci 11:168-190.

Born RT, Tootell RBH (1992) Segregation of global VS local motion processing in primate visual area MT. Invest Ophthalmol Vis Sci 33: 955.

Boussaoud D, Ungerleider LG, Desimone R (1990) Pathways for motion analysis: cortical connections of the medial superior temporal and fundus of the superior temporal visual areas in the macaque. $J$ Comp Neurol 296:462-495.

Burkhalter A, Van Essen DC (1986) Processing of color, form and disparity information in visual areas VP and V2 of ventral extrastriate cortex in the macaque monkey. J Neurosci 6:2327-2351.

Burkhalter A, Felleman DJ, Newsome WT, Van Essen DC (1986) Anatomical and physiological asymmetries related to visual areas V3 and VP in macaque extrastriate cortex. Vision Res 26:63-50.

Cusick CG, Kaas JH (1986) Interhemispheric connections of cortical, sensory and motor maps in primates. In: Two hemispheres-one brain (Lepore F, Ptito M, Jasper HH, eds), pp 83-102. New York: Liss.

Cusick CG, Kaas JH (1988) Cortical connections of area 18 and dorsolateral visual cortex in squirrel monkeys. Vis Neurosci 1:211-237.

Dawson DR, Killackey HP (1987) The organization and mutability of the forepaw and hindpaw representations in the somatosensory cortex of the neonatal cat. J Comp Neurol 256:246-256.

Desimone R, Ungerleider LG (1986) Multiple visual areas in the caudal superior temporal sulcus of the macaque. J Comp Neurol 248: 164-189.

DeYoe EA, Van Essen DC (1988) Concurrent processing streams in monkey visual cortex. Trends Neurosci 11:219-226.

Felleman DJ, Van Essen DC (1991) Distributed hierarchical processing in the primate cerebral cortex. Cereb Cortex 1:1-47.

Fiorani M, Gattass R, Rosa MGP, Sousa APB (1989) Visual area MT in the cebus monkey: location, visuotopic organization, and variability. J Comp Neurol 287:98-118.

Gallyas R (1979) Silver staining of myelin by means of physical development. Neurol Res 1:203-209.

Gattass R, Gross CG (1981) Visual topography of striate projection zone (MT) in posterior superior temporal sulcus of the macaque. J Neurophysiol 46:621-638.

Gattass R, Sousa APB, Gross CG (1988) Visuotopic organization and extent of V3 and V4 of the macaque. J Neurosci 8:1831-1845.

Gibson AR, Hansma DI, Houk JC, Robinson FR (1984) A sensitive low artifact TMB procedure for the demonstration of WGA-HRP in the CNS. Brain Res 298:235-241.

Gould JH III, Cusick CG, Pons TP, Kaas JH (1986) The relationship of corpus callosum connections to electrical stimulation maps of motor, supplementary motor, and frontal eye fields in owl monkeys. J Comp Neurol 247:297-325.

Huerta MF, Kaas JH (1990) The supplementary eye field as defined by intracortical microstimulation: connections in macaques. J Comp Neurol 293:299-330.
Huerta MF, Krubitzer LA, Kaas JH (1987) The frontal eye field as defined by intracortical microstimulation in squirrel monkeys, owl monkeys, and macaque monkeys. I. Cortical connections. J Comp Neurol 265:332-361.

Kaas JH (1982) The segregation of function in the nervous system: why do sensory systems have so many subdivisions? In: Contributions to sensory physiology (Neff WP, ed), pp 201-240. New York: Academic.

Kaas JII (1989) Why does the brain have so many visual areas? J Cogn Neurosci 1:121-135.

Kaas JH (1990) Processing areas and modules in sensory-perceptual cortex. In: Signal and sense: local and global order in perceptual maps (Edelman GM, Gall WE, Cowan WM, eds), pp 67-82. New York: Wiley.

Kaas JH, Lin CS (1977) Cortical projections of area 18 in owl monkeys. Vision Res 17:739-741.

Krubitzer LA, Kaas JH (1989) Cortical integration of parallel pathways in the visual system of primates. Brain Res 478:161-165.

Krubitzer LA, Kaas JH (1990a) Cortical connections of MT in four species of primates: areal, modular, and retinotopic patterns. Vis Neurosci 5:165-204.

Krubitzer LA, Kaas JH (1990b) Convergence of processing channels in extrastriate cortex of monkeys. Vis Neurosci 5:609-613.

Livingstone MS, Hubel DH (1988) Segregation of form, color, movement and depth: anatomy, physiology and perception. Science 240: 740-749.

Maguire WM, Baizer JS (1984) Visuotopic organization of the prelunate gyrus in rhesus monkey. J Neurosci 4:1960-1704.

Maunsell JHR, Van Essen DC (1983) The connections of the middle temporal visual area (MT) and their relationship to a cortical hierarchy in the macaque monkey. $\mathrm{J}$ Neurosci 3:2563-2586.

Maunsell JHR, Van Essen DC (1987) Topographic organization of the middle temporal visual area in the macaque monkey: representational biases and the relationship to callosal connections and myeloarchitectonic boundaries. J Comp Neurol 266:535-555.

Morel A, Bullier J (1990) Anatomical segregation of two cortical visual pathways in the macaque monkey. Vis Neurosci $4: 555-578$.

Morel A, Kaas JH (1992) Subdivisions and connections of auditory cortex in owl monkeys. J Comp Neurol 318:27-63.

Newsome WT, Allman JM (1980) Interhemispheric connections of visual cortex in the owl monkey, Aotus trivirgatus, and the bush baby, Galago senegalensis. J Comp Neurol 194:209-233.

Newsome WT, Maunsell JHR, Van Essen DC (1986) Ventral posterior visual area of the macaque: visual topography and areal boundaries. J Comp Neurol 252:139-153.

Preuss TM, Goldman-Rakic PS (1991) Architectonics of the parietal and temporal association cortex in the strepsirhine primate Galago compared to the anthropoid primate Macaca. J Comp Neurol 310: 475-506.

Schein SJ, Marrocco RT, DeMonasterio FM (1982) Is there a high concentration of color-selective cells in area V4 of monkey visual cortex? J Neurophysiol 47:193-213.

Schmued L, Kyriakidis K, Heimer L (1990) In vivo anterograde and retrograde axonal transport of the fluorescent rhodamine-dextranamin, Fluoro-Ruby, within the CNS. Brain Res 526:127-134.

Sereno MI, Allman JM (1991) Cortical visual areas in mammals. In: The neural basis of visual function, Vol 4, Vision and visual dysfunction (LeVenthal AG, ed), pp 160-172. London: Macmillan.

Sereno MI, McDonald CT, Allman JM (1987) Multiple visual areas between V2 and MT in the owl monkey. Soc Neurosci Abstr 13:625.

Sousa APB, Carmen M, Pinon GP, Gattass R, Rosa MGP (1991) Topographic organization of cortical input to striate cortex in Cebus monkey: a fluorescent tracer study. J Comp Neurol 308:665-682.

Spat -2 WB, Tigges J (1972) Experimental-anatomical studies on the "middle temporal visual area (MT)" in primates. I. Efferent corticocortical connections in the marmoset Callithrix jacchus. J Comp Neurol 146:451-464.

Steele GE, Cusick CG, Weller RE (1991) Cortical connections of the caudal subdivision of the dorsolateral area (V4) in monkeys. J Comp Neurol 306:495-520.

Tigges J, Shantha TR (1969) A stereotaxic brain atlas of the tree shrew (Tupaia glis). Baltimore: Williams and Wilkins.

Tootell RBH, Born RT (1991) Architecture of primate area MT. Soc Neurosci Abstr 17:524.

Tootell RBH, Hamilton SL, Silverman MS (1985) Topography of 
cytochrome oxidase activity in owl monkey cortex. J Neurosci 5:2786-2800.

Ungerleider LG, Desimone R (1986a) Projections to the superior temporal sulcus from the central and peripheral field representations of V1 and V2. J Comp Neurol 248:147-163.

Ungerleider LG, Desimone $\mathrm{R}$ (1986b) Cortical connections of visual area MT in the macaque. J Comp Neurol 248:190-222.

Ungerleider LG, Mishkin M (1982) Two cortical visual systems. In: Analysis of visual behavior (Ingel DJ, Goodale MA, Mansfield RJW, eds), pp 549-586. Cambridge, MA: MIT Press.

Van Essen DC, Maunsell JHR, Bixby JL (1981) The middle temporal visual area in the macaque: myeloarchitecture, connections, functional properties and topographic connections. J Comp Neurol 199: 293-326.

Wagor E, Lin CS, Kaas JH (1975) Some cortical projections of the dorsomedial visual area (DM) of association cortex in the owl monkey, Aotus trivirgatus. J Comp Neurol 163:227-250.

Wall JT, Symonds LL, Kaas JH (1982) Cortical and subcortical pro- jections of the middle temporal area (MT) and adjacent cortex in Galagos. J Comp Neurol 211:193-194.

Weller RE, Kaas JH (1987) Subdivisions and connections of inferior temporal cortex in owl monkeys. J Comp Neurol 256:137-172.

Weller RE, Steele GE (in press) Cortical connections of subdivisions of inferior temporal cortex in squirrcl monkeys. J Comp Neurol, in press.

Weller RE, Wall JT, Kaas JH (1984) Cortical connections of the middle temporal visual area (MT) and the superior temporal cortex in owl monkeys. J Comp Neurol 228:81-104.

Weller RE, Steele GE, Cusick CG (1991) Cortical connections of dorsal cortex rostral to V-II in squirrel monkeys. J Comp Neurol 306:521-537.

White PF, Way WL, Trevor AJ (1982) Ketamine-its pharmacology and therapeutic uses. Anesthesiology 56:119-136.

Wong-Riley M (1979) Changes in the visual system of monocularly sutured or enucleated cats demonstrable with cytochrome-oxidase histochemistry. Brain Res 171:11-28. 